\title{
Validation of satellite-based noontime UVI with NDACC ground-based instruments: influence of topography, environment and satellite overpass time
}

\author{
Colette Brogniez $^{1}$, Frédérique Auriol ${ }^{1}$, Christine Deroo $^{1}$, Antti Arola ${ }^{2}$, Jukka Kujanpää ${ }^{3}$, Béatrice Sauvage ${ }^{1, a}$, \\ Niilo Kalakoski ${ }^{3}$, Mikko Riku Aleksi Pitkänen ${ }^{2,4}$, Maxime Catalfamo ${ }^{1}$, Jean-Marc Metzger ${ }^{5}$, Guy Tournois ${ }^{6}$, and \\ Pierre Da Conceicao $^{6}$ \\ ${ }^{1}$ Laboratoire d'Optique Atmosphérique, Université Lille 1 Sciences et Technologies, Villeneuve d'Ascq, France \\ ${ }^{2}$ Finnish Meteorological Institute, Yliopistonranta 1 F, P.O. Box 1627, 70211 Kuopio, Finland \\ ${ }^{3}$ Finnish Meteorological Institute, Earth Observation Unit, P.O. Box 503, 00101 Helsinki, Finland \\ ${ }^{4}$ Department of Applied Physics, University of Eastern Finland, Yliopistonranta 1 F, 70210 Kuopio, Finland \\ ${ }^{5}$ UMS 3365 - OSU Réunion, Université de La Réunion, Saint-Denis, Réunion, France \\ ${ }^{6}$ UMS 3470 - OSU Pytheas, Observatoire de Haute-Provence, Saint-Michel l'Observatoire, France \\ ${ }^{\text {a }}$ formerly at: Laboratoire d'Optique Atmosphérique, Université Lille 1 Sciences et Technologies, Villeneuve d'Ascq, France
}

Correspondence to: Colette Brogniez (colette.brogniez@univ-lille1.fr)

Received: 25 March 2016 - Published in Atmos. Chem. Phys. Discuss.: 26 April 2016

Revised: 25 October 2016 - Accepted: 28 October 2016 - Published: 6 December 2016

\begin{abstract}
Spectral solar UV radiation measurements are performed in France using three spectroradiometers located at very different sites. One is installed in Villeneuve d'Ascq, in the north of France (VDA). It is an urban site in a topographically flat region. Another instrument is installed in Observatoire de Haute-Provence, located in the southern French Alps (OHP). It is a rural mountainous site. The third instrument is installed in Saint-Denis, Réunion Island (SDR). It is a coastal urban site on a small mountainous island in the southern tropics. The three instruments are affiliated with the Network for the Detection of Atmospheric Composition Change (NDACC) and carry out routine measurements to monitor the spectral solar UV radiation and enable derivation of UV index (UVI). The ground-based UVI values observed at solar noon are compared to similar quantities derived from the Ozone Monitoring Instrument (OMI, onboard the Aura satellite) and the second Global Ozone Monitoring Experiment (GOME-2, onboard the Metop-A satellite) measurements for validation of these satellite-based products. The present study concerns the period 2009-September 2012, date of the implementation of a new OMI processing tool. The new version (v1.3) introduces a correction for absorbing aerosols that were not considered in the old version (v1.2).
\end{abstract}

Both versions of the OMI UVI products were available before September 2012 and are used to assess the improvement of the new processing tool. On average, estimates from satellite instruments always overestimate surface UVI at solar noon. Under cloudless conditions, the satellite-derived estimates of UVI compare satisfactorily with ground-based data: the median relative bias is less than $8 \%$ at VDA and $4 \%$ at SDR for both OMI v1.3 and GOME-2, and about $6 \%$ for OMI v1.3 and $2 \%$ for GOME- 2 at OHP. The correlation between satellite-based and ground-based data is better at VDA and OHP (about 0.99) than at SDR (0.96) for both space-borne instruments. For all sky conditions, the median relative biases are much larger, with large dispersion for both instruments at all sites (VDA: about $12 \%$; OHP: $9 \%$; SDR: $11 \%)$. Correlation between satellite-based and ground-based data is still better at VDA and OHP (about 0.95) than at SDR (about 0.73 ) for both satellite instruments. These results are explained considering the time of overpass of the two satellites, which is far from solar noon, preventing a good estimation of the cloud cover necessary for a good modelling of the UVI. Site topography and environment are shown to have a non-significant influence. At VDA and OHP, OMI 
v1.3 shows a significant improvement with respect to v1.2, which did not account for absorbing aerosols.

\section{Introduction}

Monitoring of UV solar radiation at the surface is a necessary and important task to characterize the impact of atmospheric composition change, which is the goal, for example, of the Network for the Detection of Atmospheric Composition Change (NDACC) and of the Global Atmosphere Watch Programme (GAW). Indeed, UV radiation affects the biosphere having both benefits and risks (detrimental effects) whose relative importance depends strongly on latitude and season. Currently, approximately 30 sites in the Northern Hemisphere and only 8 in the Southern Hemisphere perform spectral UV measurements. Observations at northern midlatitudes help complete geographical coverage from other sites. Observations from Réunion Island, close to the Tropic of Capricorn, are useful as well because only few sites exist in the low latitudes.

Due to the scarcity of surface-based UV measurements, which results in sparse geographical coverage, satellite platforms are very useful since they provide global data. Surface UV radiation from satellite radiance measurements is retrieved via radiative transfer codes whose input data are ozone and aerosol contents, surface albedo and cloudiness. Some of these data are products of the instrument itself (ozone, cloudiness) while others come from climatologies (aerosol content, albedo). Differences between the data of the two satellite instruments that will be used in this work (OMI, the Ozone Monitoring Instrument, and GOME-2, the second Global Ozone Monitoring Experiment) are detailed below.

Despite their extensive geographical coverage, satellitebased (SB) data products are affected by measurement uncertainties, as are ground-based (GB) products. However, SB data are also affected by modelling uncertainties. Moreover, due to their rather coarse spatial resolution, SB data sometimes do not capture fine-scale phenomena. Overall, various sites are useful for assessing the satellite data products in various conditions, including various latitudes, land covers, altitudes and climates. However, validation exercises are difficult to achieve due to differences in temporal and spatial resolutions of GB and SB data products. Extensive comparison studies between surface UV provided by OMI and GB measurements have been previously made (Tanskanen et al., 2007; Buchard et al., 2008; Ialongo et al., 2008; Weihs et al., 2008). Those studies dealt with version 1.2, which did not account for the influence of absorbing aerosols, implying a positive bias in OMI product. The OMI product has been tentatively corrected by several methods (Kazadzis et al., 2009a; Arola et al., 2009; Buntoung and Webb, 2010; Antón et al., 2012). From the comparisons against GB measurements, the OMI surface UV index (UVI) at sites with low amounts of absorbing aerosols has been shown to be an overestimation of $0-10 \%$. Alternatively, at sites with significant influence from absorbing aerosols, OMI surface UVI show a larger positive bias of up to $50 \%$. All these OMI validations, apart from Buntoung and Webb (2010), were conducted using data collected at the time of the satellite overpass. Currently, only one validation study is available for GOME-2, but it only concerns daily doses (Kalakoski, 2009). For both satellite instruments, the previous validations address data up to 2008, except Antón et al. (2012) for OMI. Muyimbwa et al. (2015) and Bernhard et al. (2015) address more recent OMI data. In the present study, validations are conducted using data at noon, when the UVI is maximum for cloud-free conditions, over a more recent period at three French sites, including a new southern site.

The Saint-Denis site on Réunion Island is characterized by the proximity of the ocean, a complex topography and a frequent occurrence of orographic clouds forming at around midday. This site may be not representative of satellite pixel because a large part of the area contributing to the satellite measurement is over the ocean, where the cloud cover is likely different from that over the mountainous island. Due to its tropical location (high sun elevation in summer and low total ozone column) the UV radiation level is very high. Overpass by OMI occurs in the afternoon and GOME-2 overpass occurs in the morning. The two other metropolitan sites are characterized by the presence of absorbing aerosols, on average in larger quantity at Villeneuve d'Ascq than at Observatoire de Haute-Provence, but less absorbing. Their midlatitude situation implies lower UV radiation levels than in the tropics (lower sun elevation in summer and larger total ozone column). For both sites, overpass occurs close to noontime for OMI and in the morning for GOME-2.

OMI and GOME-2 websites make available UVI data and maps at solar noon, when values are generally close to the maximum and more risky for health; therefore, comparison with ground-based UVI is carried out in this study at noontime. Validations of satellite-based estimates with ground-based measurements are conducted under cloudless and all sky conditions for about 4 years (January 2009September 2012), until the date of the implementation of a new OMI processing tool. The new version (v1.3) introduces a correction for absorbing aerosols that were not considered in the old version (v1.2). The whole archive has been reprocessed with OMI v1.3, so both versions of the OMI UVI products are available before September 2012 and are used in this work to assess the effect of the absorbing aerosol correction.

The influence of the cloudiness assumed by each satellite algorithm on the SB-GB UVI comparison is discussed. The influence of the site topography and environment is studied as well.

The ground-based spectroradiometers and the OMI and GOME-2 instruments are described in Sect. 2 along with the methodologies for deriving surface UVI. Section 3 presents 
the comparisons between the satellite-based and the groundbased UVI in various conditions and comparisons between measured and modelled UVI for cloudless conditions. Conclusions are provided in Sect. 4.

\section{Instruments}

\subsection{Ground-based instruments}

\subsubsection{Description}

The UV measurements used here come from three French stations: Villeneuve d'Ascq $\left(50.61^{\circ} \mathrm{N}, 3.14^{\circ} \mathrm{E} ; 70 \mathrm{~m}\right.$ above sea level (a.s.l.), referred to as VDA in the following), Observatoire de Haute-Provence $\left(43.93^{\circ} \mathrm{N}, 5.70^{\circ} \mathrm{E} ; 686 \mathrm{~m}\right.$ a.s.l., referred to as OHP) and Saint-Denis, Réunion Island $\left(20.9^{\circ} \mathrm{S}, 55.5^{\circ} \mathrm{E} ; 85 \mathrm{~m}\right.$ a.s.l., referred to as SDR). The three sites are each equipped with a double monochromator Bentham DTMc300. The instruments are thermally regulated. They provide global irradiance spectra in the $280-450 \mathrm{~nm}$ wavelength range with a $0.5 \mathrm{~nm}$ sampling step and a full width at half maximum (FWHM) of about $0.5 \mathrm{~nm}$. Scans are performed every $15 \mathrm{~min}$ (at SDR and OHP in 2009-2010), or $30 \mathrm{~min}$ (at VDA and OHP in 2011-2012). Scan duration is about $5 \mathrm{~min}$.

\subsubsection{Data processing}

The instruments are regularly calibrated with standard $1000 \mathrm{~W}$ lamps traceable to National Institute of Standards and Technology. After calibration, the wavelength misalignment is corrected via a software tool developed at Laboratoire d'Optique Atmosphérique (Houët, 2003) and improved during an intercomparison campaign with the QASUME (Quality Assurance of Spectral Ultraviolet Measurements in Europe, Gröbner et al., 2005) instrument held in 2010. The cosine correction (Bernhard and Seckmeyer, 1999) is then carried out leading to the measured irradiance $I$ at wavelength $\lambda$.

The erythemally weighted UV, $\mathrm{UV}_{\text {ery }}$, is obtained by integrating the irradiance $I(\lambda)$ weighted by the erythema action spectrum $A(\lambda)$ over the wavelength. The erythema action spectrum used is from Commission Internationale de l'Éclairage (CIE) (Diffey and McKinlay, 1987). The UV index is then derived by dividing $\mathrm{UV}_{\text {ery }}$ (in $\mathrm{W} \mathrm{m}^{-2}$ ) by $25 \times 10^{-3} \mathrm{~W} \mathrm{~m}^{-2}$.

Irradiance uncertainty is estimated relying on Bernhard and Seckmeyer (1999). It results from uncertainties in the absolute calibration (including spectral irradiance lamp uncertainty provided by the lamp supplier, imprecision of adjustments and wavelength misalignment) and in the field measurements (imprecision of diffuser horizontality, uncertainty in cosine correction and in wavelength shift correction). During the QASUME campaigns held for the three instruments, biases were observed: on average about $10 \%$ for
VDA and OHP instruments and $3 \%$ at SDR (local instrument measurements lower than those of QASUME; reports available at http://www.pmodwrc.ch/wcc_uv/wcc_uv.php?topic= qasume_audit). Following these results, the VDA and OHP lamps have been recalibrated in July 2012 at the World Radiation Center, Davos, Switzerland, and all the data were reprocessed. A NDACC intercomparison campaign held in July 2015 in Hanover, Germany, and further analysis have shown that the measurements are 3-4\% lower than the reference measurements, and that is within the reference measurement uncertainty. The SDR lamp irradiance has been adjusted to the QASUME irradiance (May 2013), and all the data were reprocessed.

The irradiance uncertainty leads to a UVI uncertainty for a coverage factor $k=2$ of $5.3 \%$ at VDA and OHP and $5 \%$ at SDR. The remaining biases observed at VDA and OHP are thus within these uncertainties.

All instruments are affiliated with NDACC.

\subsection{Satellite-based instruments}

\subsubsection{OMI}

\section{Description}

The OMI instrument on the Aura platform, launched in July 2004 into a sun-synchronous quasi-polar orbit, is a nadirviewing $\mathrm{UV} /$ visible spectrometer dedicated to the monitoring of atmospheric ozone, trace gases, aerosol, cloudiness and surface UV. OMI measures the solar radiation backscattered by the atmosphere with a spectral resolution of about $0.45 \mathrm{~nm}$ in the UV and a spatial resolution at nadir of $13 \mathrm{~km}$ (along track) $\times 24 \mathrm{~km}$ (across track) (Levelt et al., 2006). Thanks to the Aura orbit and the large OMI swath width of $2600 \mathrm{~km}$, the daily geographic coverage is global.

\section{Data processing}

The OMI version 1.2 algorithm first estimates clear sky surface UV irradiance via a radiative transfer model using total ozone column, derived from measurements of OMI itself via another dedicated algorithm, with surface albedo provided by a climatology (Tanskanen, 2004), a high-resolution extraterrestrial solar spectrum and climatological profiles of ozone and temperature (Krotkov et al., 2002). Secondly, nonabsorbing aerosols and cloud cover are accounted for as a correction factor to estimate the actual surface UV radiation. The cloud cover parameter used is the cloud optical depth (COD) determined from OMI measurements. For products estimated at local noontime, change in cloudiness between the OMI local overpass time and noontime is not taken into account. This modelling is performed for solar zenith angles (SZAs) lower than $85^{\circ}$. Finally, UVI is derived from spectral irradiance. 
OMI-derived UVI data used here come from the OMUVB product available for overpass sites from http://avdc.gsfc. nasa.gov/index.php?site $=595385375 \& \mathrm{id}=79$.

According to earlier validation works performed with OMI version 1.2 (Arola et al., 2009; Kazadzis et al., 2009a, b; Antón et al., 2012), a large part of the high positive bias between OMI UVI and GB data is due to absorbing aerosols. The new version (v1.3) accounts for absorbing aerosols via an aerosol climatology (Kinne et al., 2013), which is used in a correction factor (CF) applied to v1.2 UV estimates (Arola et al., 2009).

Uncertainty in OMI-derived UVI is due to uncertainties in the clear sky irradiance modelling (depending on ozone, surface albedo) and in the cloud-aerosol correction factor. According to Krotkov et al. (2002), the resulting uncertainty is about $5 \%(10 \%$ for $k=2)$ in clear sky conditions and about $7 \%(14 \%)$ in cloudy conditions. When the satellite overpass occurs at a time significantly different from local noon, an additional uncertainty is added because UVI is given at noontime and the correction factor is estimated at the time of the overpass. In the presence of absorbing aerosols, the estimated uncertainty for v1.2 increases to about $15-25 \%$ (30-50\%), depending on aerosol type and load. In the latest version, this systematic overestimation has been significantly reduced. According to Arola et al. (2009), the use of the absorbing aerosol correction results in a significantly reduced bias by $5-20 \%$.

\subsubsection{GOME-2}

\section{Description}

GOME-2 on the Metop-A platform was launched on October 2006 into a sun-synchronous quasi-polar orbit. The spectrometer is a nadir-scanning instrument measuring the solar radiation backscattered by the atmosphere with a spectral resolution of about $0.27 \mathrm{~nm}$ in the UV. In the default scanning mode, the swath width is $1920 \mathrm{~km}$, enabling global coverage in 1.5 days. The spatial resolution is $40 \mathrm{~km}$ (along track) $\times 80 \mathrm{~km}$ (across track). The spatial resolution is kept constant throughout the swath by adjusting the speed of the scanning mirror (Munro et al., 2016).

\section{Data processing}

The GOME-2 algorithm proceeds similarly to OMI algorithm, with slight differences. Surface UV irradiance is estimated via a radiative transfer model using total ozone column, derived from GOME-2 measurements via another dedicated algorithm; surface albedo from the same climatology as the OMI algorithm; an extraterrestrial solar spectrum; and climatological profiles of ozone, temperature, aerosols and clouds (Kujanpää and Kalakoski, 2015). Aerosol properties come from the Global Aerosol Data Set (GADS) (Köpke et al., 1997) and aerosol optical thickness comes from the cli- matology of Kinne (2007). Instantaneous cloud optical depth is derived via interpolation of COD retrieved from measurements of AVHRR-3/Metop-A (which is on the same platform as GOME-2, having a morning orbit and the same local overpass time) and AVHRR-3 aboard NOAA satellites on the afternoon orbit (NOAA-18 until 3 June 2009 and then on NOAA-19). Depending on the station latitude, two or more AVHRR overpasses occur, making two or more COD values available. All input data are mapped to a regular $0.5^{\circ} \times 0.5^{\circ}$ latitude-longitude grid. UVI is derived from spectral irradiance and given on the same grid.

For the current study, O3M SAF offline surface UV (OUV) products were reprocessed using the algorithm version 1.13 with a special option to store diurnal COD values, which are not included in the standard product.

Uncertainty in GOME-2-derived UVI is due to uncertainty in the irradiance modelling (depending on ozone, surface albedo, cloud and aerosols). The resulting uncertainty is about $8 \%(16 \%)$ in clear sky conditions and about $10-20 \%$ (20-40\%) in cloudy conditions, depending on the number of COD values available. As for OMI, the largest contribution to the uncertainty comes from the cloudiness estimate because UVI is given at noon rather than at the satellite overpass time. In the presence of absorbing aerosols, the uncertainty increases to about 30-35\% (60-70\%), depending on aerosol type and content (Kujanpää, 2013).

\section{Results}

Due to their limited spatial resolution, space-borne measurements represent an average value for the observed pixel. Thus, when the cloud cover is not homogenous in the pixel, satellite data should not be directly compared to instantaneous ground-based measurements. For comparison at overpass time, the effect of the cloud variability within a satellite sensor pixel can be accounted for by averaging GB measurements over a time interval around the time of overpass. Here, comparisons are conducted at noontime, and the cloudiness measurements used in OMI and GOME-2 algorithms are not actual values at noontime. Nevertheless, for all sky conditions (AS), GB UVI measurements have been averaged over a time interval around noontime. Several time intervals have been tested and the hourly average of GB values has been selected as a better representative of spatial measurements for both space-borne instruments. Though the GOME-2 pixel is larger than the OMI pixel, a mean over a larger time interval is not valuable since it would introduce a low bias in the GB product at solar noon (indeed, UVI is generally maximum at noon).

For cloudless conditions (CS), to avoid introducing a low bias in the GB product at solar noon (see above), no average was calculated. The selection of CS measurements at noontime cannot be made via cloud information available in the OMI data files since the COD corresponds to overpass 
time, and for GOME-2, cloud information is interpolated at noon from AVHRR data (see Sect. 2.2.2); therefore, the COD value may not really be valid. Thus, CS selection is based on the examination of the GB UVI measurements. Two criteria are set up to declare the sky as cloudless: (i) the shape of the curve of the UVI diurnal variations around noon must be smooth (visual inspection), and (ii) the UVI relative dispersion around the hourly mean must be less than $5 \%$, with this value being an estimate of the UVI variation due to SZA variation around noontime (estimation derived from modelling). This second criterion is checked automatically. In addition, images from the SEVIRI sensor on the MSG satellite must show cloud-free conditions close to the measurement time. This method is not perfect because a nearly constant thin cloud cover can be mistaken for cloud-free conditions.

We have considered two limits (100 and $10 \mathrm{~km})$ for the distance between the GB station and the cross-track position (CTP) for OMI and the grid cell centre point for GOME-2.

Satellite-based and ground-based data sets are compared by computing the UVI difference (SB-GB), the UVI relative difference (SB-GB)/GB) expressed in percent, and by plotting correlation diagrams of UVI. The following statistics parameters are used to quantify the agreement: mean and root mean square of the difference, mean, root mean square and standard deviation of the relative difference. Since the difference/relative difference distributions are skewed, we have also used the median and the 10th and 90th percentiles. All these quantities are defined in the Appendix. In addition, the correlation coefficient and the equation of the regression line obtained via a bivariate method (York et al., 2004) are estimated. These statistical parameters are common in such validation studies (for example, Tanskanen et al., 2007; Ialongo et al., 2008; Weihs et al., 2008; Kalakoski, 2009; Kazadzis et al., 2009a; Muyimbwa et al., 2015; Bernhard et al., 2015).

The comparisons between SB and GB UVI are first carried out considering all the UVI pairs for each satellite sensor for $100 \mathrm{~km}$ limit distance. In order to interpret the biases observed, radiative transfer calculations are performed for cloudless conditions. Then, other comparisons are made for $10 \mathrm{~km}$ limit distance and with a filter on altitude. Finally, to enable a comparison of the performances of the satellite sensors, an additional study restricted to common dates is conducted.

\subsection{VDA}

At this northern midlatitude site, OMI overpasses occur from $0.5 \mathrm{~h}$ before to $2.5 \mathrm{~h}$ after solar noon. The GOME- 2 overpasses take place in the morning from 3 to $0.5 \mathrm{~h}$ before solar noon. The VDA site, located in a topographically flat region, is characterized by rather high total ozone columns (on average in the 250-450 DU range) and by the presence of absorbing aerosols of pollutant origin. The surface albedo at $360 \mathrm{~nm}$, provided in the OMUVB database, exhibits a weak seasonality in the 0.03-0.07 range.
For both satellite instruments, the distance between the ground station and the CTP/grid cell centre point is first chosen smaller than or equal to $100 \mathrm{~km}$.

Comparison results for AS conditions are shown in Fig. 1 for both satellite instruments: the upper panels present OMI v1.3 and the lower panels GOME-2. Histograms of the percent relative differences between SB and GB UVI data are located to the left and correlation diagrams are located to the right. Crosses circled in blue (for OMI) or turquoise (GOME2) correspond to a COD of less than or equal to 1 . Notice that the GOME-2 data set is smaller than the OMI data set because there is only one value per day and no value when SZA at noon is larger than $70^{\circ}$. The data show a medium dispersion around relative difference means (SD nearly $40 \%$, means nearly $21 \%$ ), the correlation between SB and GB UVI is strong (correlation coefficients $r \sim 0.95$ ) and the regression lines have a slope larger than unity $(1.08 \pm 0.01$ for OMI, $1.12 \pm 0.01$ for GOME-2) with a small intercept. Satellitederived UVI is larger than GB UVI (positive relative difference) in $78 \%$ of cases for OMI and in $73 \%$ for GOME- 2 . When the COD is smaller than or equal to 1 (circled crosses) the UVI relative difference is almost always positive for OMI (Fig. 1b), but is less so for GOME-2 (Fig. 1d). Satellitederived UVI smaller than GB UVI (negative relative difference) can occur when the COD is large, as seen in Fig. 3a and c where the UVI relative difference is plotted vs. the COD retrieved from satellite instruments. These negative UVI relative differences for large COD values are observed for both low and high UVI (UVI $\geq 3$ : blue circles for OMI, green circles for GOME-2), especially for OMI. Negative UVI differences for small $\mathrm{COD}$ values $(\mathrm{COD} \leq 1)$ are sometimes observed for GOME-2, which can be related to the SZA at the time of satellite overpass. Indeed, as seen in Fig. $4 a$ and c, a filter set up on SZA at overpass shows that SZA $>60^{\circ}$ corresponds to UVI $<3$ and to many negative relative differences for both OMI and GOME-2 (blue and green circles). Approximate values of the median relative biases are $12.5 \%$ for OMI and $12.1 \%$ for GOME-2. The 90th percentiles $\left(p_{90}\right)$ indicate that $10 \%$ of the cases correspond to relative differences larger than about 71 and $64 \%$ for OMI and GOME-2, respectively (Fig. 1 caption). This $10 \%$ of cases for which the SB UVI overestimate the UVI at the surface are identified as red and violet crosses in Fig. $3 \mathrm{a}$ and c, i.e. correspond often to UVI lower than 3 and to a large COD. The 10th percentiles $\left(p_{10}\right)$ indicate that $10 \%$ of the cases correspond to $\mathrm{OMI}$ and GOME-2 underestimations of more than about $15 \%$ (Fig. 1 caption), associated also with UVI $<3$ and with a large COD (Fig. 3a and c).

Figure 2 shows the results obtained for CS conditions. The dispersion around relative difference means is weak (SD $<10 \%$, means $<8 \%$ ), the correlations between SB and GB UVI are very strong $(r \sim 1)$, and the slopes of the regression lines are slightly larger than for AS conditions $(1.10 \pm 0.01$ for OMI, $1.14 \pm 0.02$ for GOME-2) with small intercepts. Satellite-derived UVI is still generally larger than 

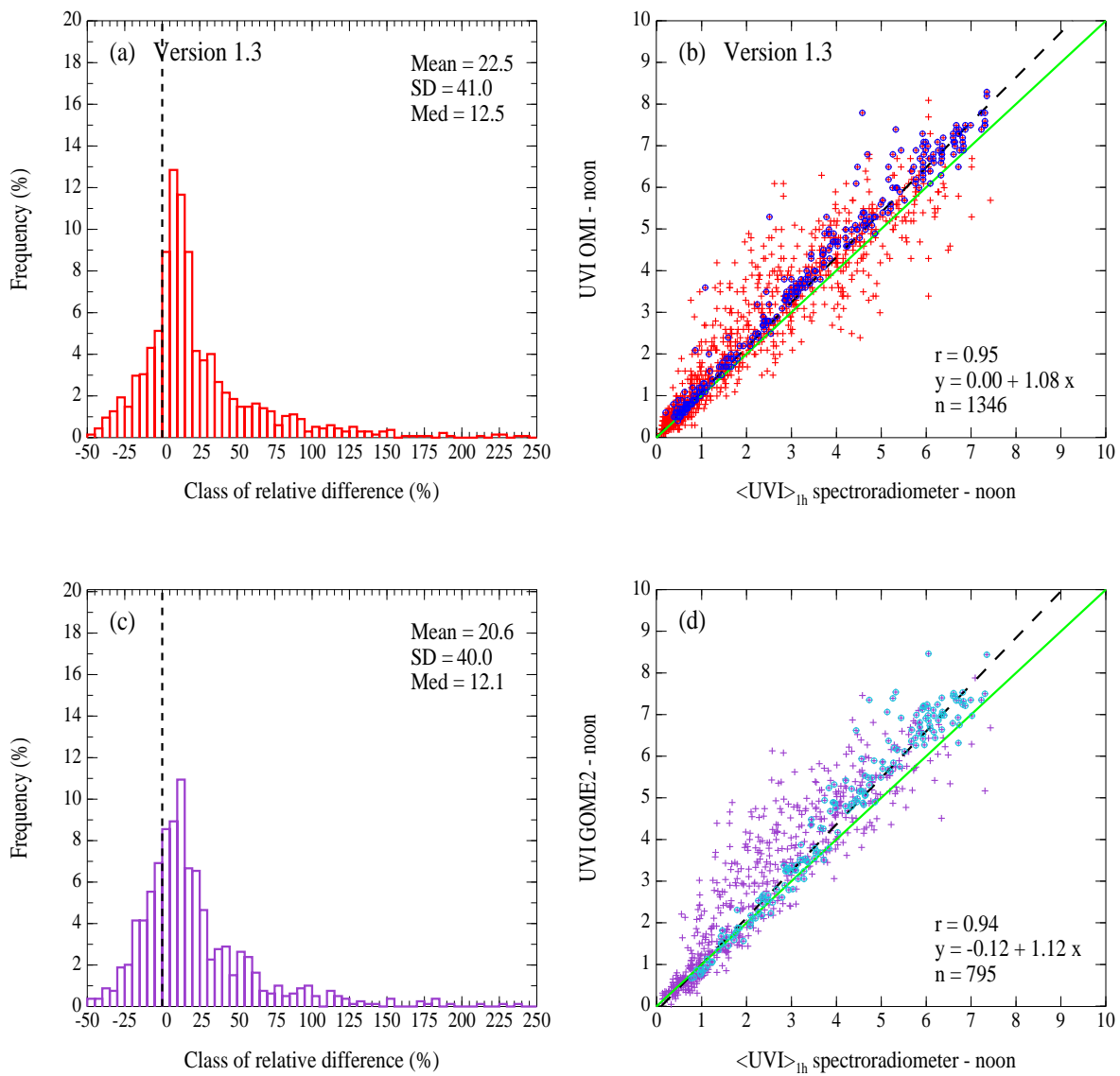

Figure 1. OMI v1.3 (top panels) and GOME-2 (bottom panels) vs. GB observations for distance $\leq 100 \mathrm{~km}$ and for AS conditions at VDA. GB measurements are averages over $1 \mathrm{~h}$ around local noon. $(\mathbf{a}, \mathbf{c})$ Histograms of percent relative difference $(100 \times(\mathrm{SB}-\mathrm{GB}) / \mathrm{GB})$ binned with $5 \%$ interval. Few statistics parameters are indicated. $(\mathbf{b}, \mathbf{d})$ Scatter plots of satellite estimates vs. GB measurements. Circled crosses correspond to COD $\leq 1$ (COD at overpass for OMI v1.3 and at noon for GOME-2). The equation of the regression line (dashed line) and the correlation coefficient are indicated. The green solid line is the first bisector. Percentiles for OMI: $p_{10}=-14.9 \%, p_{90}=71.4 \%$; for GOME-2: $p_{10}=-16.8 \%, p_{90}=64.3 \%$.

GB UVI ( $~ 92 \%$ of cases for OMI, $80 \%$ for GOME-2) and this corresponds almost always to $\mathrm{COD} \leq 1$ (circled crosses), as seen also in Fig. $3 b$ and d. These low COD values indicate that the satellite algorithms provide a good estimate of the actual cloudiness. As with GOME-2 for AS conditions, for UVI values smaller than about 3, GOME-2 values are generally smaller than GB values (Fig. 3d), and these cases correspond to SZA $>60^{\circ}$ (Fig. 4d). Only two such cases are observed for OMI (Figs. $3 b$ and $4 b$ ). Both satellite sensors demonstrate a positive median relative bias (SB UVI $>$ GB UVI) of about $8.5 \%$. The number of CS cases is not very large for GOME-2 comparison (37), but the results are statistically robust. A total of $10 \%$ of the cases correspond to an SB overestimation of more than 16 and $13 \%$ for OMI and GOME-2, respectively ( $p_{90}$, Fig. 2 caption). $p_{10}$ values indicate that $10 \%$ of the cases correspond to an OMI underestimation $\left(p_{10}=0 \%\right.$, i.e. $10 \%$ of the cases show a negative relative difference) and to more than $10 \%$ of GOME-2 underestimations. For GOME-2, most of these cases correspond to UVI $<3$ (violet crosses in Fig. 3d).

The statistics of the results are reported in Table 1 for AS conditions and in Table 2 for CS conditions. The median bias is positive and small for both instruments: 0.21 for OMI and 0.33 for GOME-2 for AS conditions, 0.32 for OMI and 0.39 for GOME-2 for CS conditions.

A seasonal effect on differences is observed for both instruments with smaller values in winter which correspond to small UVI. UVI relative differences for OMI show no seasonal effect (the large UVI differences being divided by high UVI). On the other hand, GOME-2 UVI relative differences exhibit seasonal variations, which is due to negative values related to a small UVI and large SZA occurring mostly in winter rather than in other seasons (not shown). Surface albedo seasonality seems too weak to explain this behaviour.

These performances of the two satellite instruments should not be compared because the temporal coverage is not the 
Table 1. Summary of UVI OMI-GOME-2 validation results at the three sites for distances between the station and the CTP/grid cell centre point $\leq 100 \mathrm{~km}$ and for all sky conditions. Results for the two OMI versions are presented. $n$ is the number of points, $r$ is the correlation coefficient. We have indicated the slope (uncertainty in parentheses) and intercept (interc.) of the regression line. See the statistics definitions in the Appendix.

\begin{tabular}{|c|c|c|c|c|c|c|c|c|c|c|c|c|}
\hline & $n$ & $\begin{array}{r}\text { Mean } \\
\text { bias } \\
\text { UVI }\end{array}$ & $\begin{array}{r}\text { Median } \\
\text { bias } \\
\text { UVI }\end{array}$ & $\begin{array}{r}\text { RMS } \\
\text { UVI }\end{array}$ & $\begin{array}{r}\text { Mean } \\
\text { rel bias } \\
\%\end{array}$ & $\begin{array}{r}\text { Median } \\
\text { rel bias } \\
\%\end{array}$ & $\begin{array}{r}\mathrm{rRMS} \\
\%\end{array}$ & $p_{10}$ & $p_{90}$ & $\begin{array}{l}\text { Slope } \\
\text { (unc.) }\end{array}$ & $\begin{array}{r}\text { Interc. } \\
\text { UVI }\end{array}$ & $r$ \\
\hline OMI v1.2/spectro & 1356 & 0.57 & 0.38 & 0.94 & 31.5 & 20.9 & 54.8 & -7.8 & 84.9 & $\begin{array}{r}1.17 \\
(0.01)\end{array}$ & -0.01 & 0.95 \\
\hline GOME-2/spectro & 795 & 0.50 & 0.33 & 0.90 & 20.6 & 12.1 & 45.0 & -16.8 & 64.3 & $\begin{array}{r}1.12 \\
(0.01)\end{array}$ & -0.12 & 0.94 \\
\hline \multicolumn{13}{|c|}{ OHP } \\
\hline OMI v1.2/spectro & 1313 & 0.91 & 0.83 & 1.29 & 31.3 & 19.7 & 57.2 & 1.7 & 72.4 & $\begin{array}{r}1.14 \\
(0.01)\end{array}$ & 0.07 & 0.96 \\
\hline \multicolumn{13}{|c|}{ SDR } \\
\hline OMI v1.2/spectro & 782 & 1.30 & 0.80 & 2.71 & 27.9 & 10.7 & 62.8 & -12.5 & 80.9 & $\begin{array}{r}0.86 \\
(0.02)\end{array}$ & 1.61 & 0.72 \\
\hline OMI v1.3/spectro & 774 & 1.39 & 0.78 & 2.70 & 29.0 & 10.4 & 64.2 & -9.2 & 85.9 & $\begin{array}{r}0.91 \\
(0.02)\end{array}$ & 1.36 & 0.74 \\
\hline GOME-2/spectro & 642 & 1.56 & 0.87 & 2.81 & 34.6 & 10.8 & 75.3 & -6.0 & 99.9 & $\begin{array}{r}0.78 \\
(0.03)\end{array}$ & 2.45 & 0.71 \\
\hline
\end{tabular}

same. Another study conducting a comparison of the performances is carried out further.

The overpass of both satellite instruments occurs sometimes quite far from noon. Surprisingly, no correlation between the UVI relative difference and the time difference between overpass and noon is observed, neither for AS nor for CS conditions (not shown).

For CS conditions, radiative transfer (RT) computations are carried out to understand the positive biases observed. We use DISORT (DIScrete Ordinates Radiative Transfer) code for SZA $<70^{\circ}$ (Stamnes et al., 1988; Van Weele et al., 2000). We use SZA, the extraterrestrial solar spectrum from Dobber et al. (2008), and Paur and Bass (1985) ozone absorption cross sections. For the other input parameters, we take the total ozone column (TOC) from OMI (OMTO3), aerosol data from the sun photometers of the AERONET/PHOTONS network (Holben et al., 1998) (we use daily or monthly means of the aerosol optical depth (AOD) at $440 \mathrm{~nm}$, the Angström exponent (between 440 and $870 \mathrm{~nm}$ ) to derive the spectral AOD, the single scattering albedo (SSA) at $440 \mathrm{~nm}$ ) and the surface albedo from Feister and Grewe (1995). The other input parameters used in the RT model are the midlatitude ozone, temperature and pressure profiles. Note that the sun photometers are operating next to the spectroradiometers.

We have compared the simulated UVI to both OMI and GB UVI for several cloud-free cases. The histograms of the percent relative difference between the computed UVI and the measured one are reported in Fig. 5a for GB UVI and Fig. 5b for OMI. GB UVI measurements are $1.7 \%$ lower and OMI UVI are $4.7 \%$ higher than the simulated UVI, each value being within GB and OMI measurement uncertainty, respectively. Since the TOC is the same for both modelling and OMI, this overestimation of OMI UVI might be mainly related to aerosol parameters and surface albedo, though this parameter value is small. Of course part of the bias might come from differences between the two RT models used and also between the other input parameters. Kazadzis et al. (2009b) concluded also with an overestimation due to aerosol variability (in time and space). Of course, we have to keep in mind that modelling computations are affected by uncertainties.

For this previous modelling, we have chosen OMTO3 but other TOC data could be used, such as the TOC derived from the GB spectra following the method described 

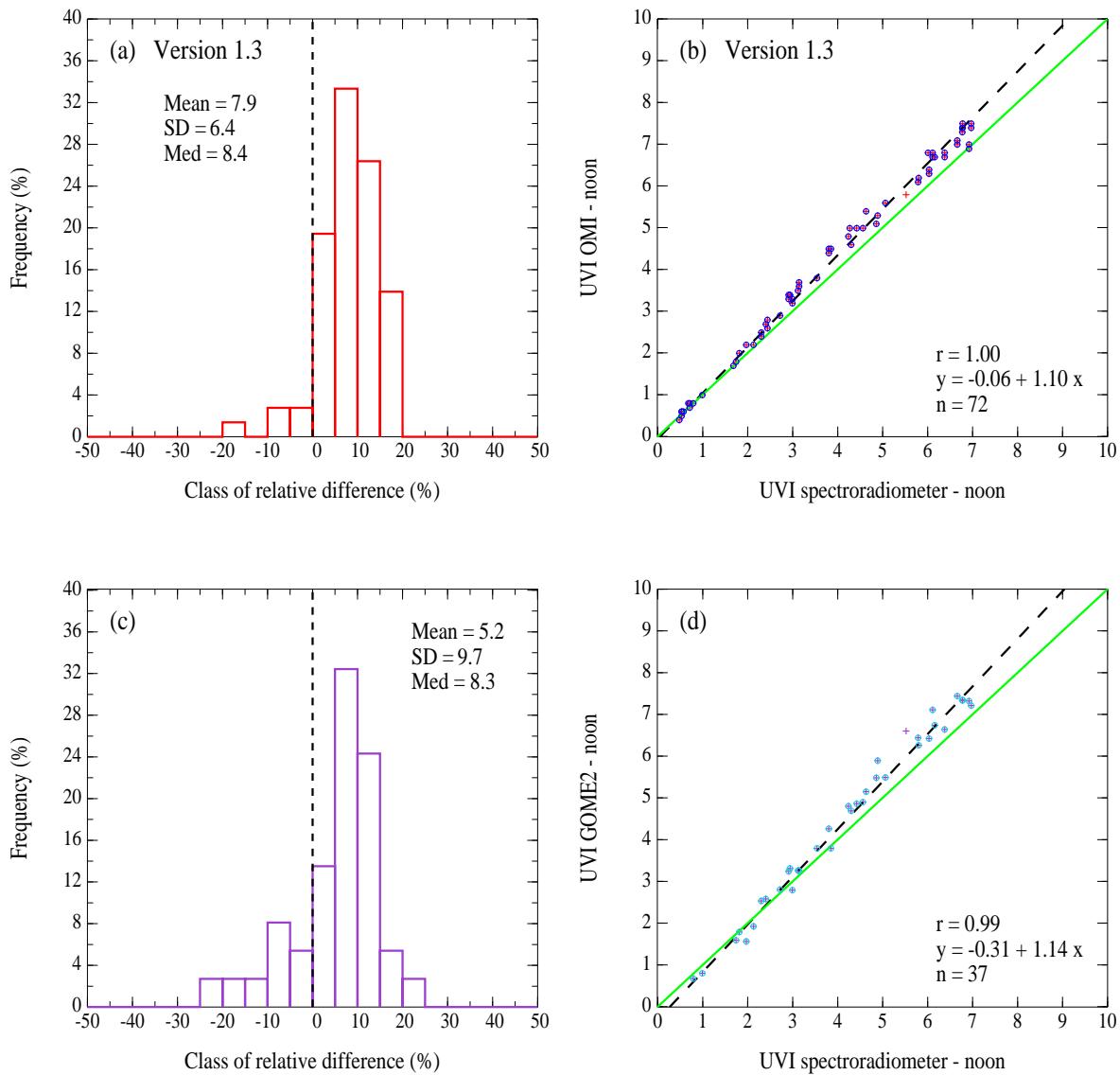

Figure 2. Same as Fig. 1 but for CS conditions at VDA. Percentiles for OMI: $p_{10}=0.0 \%, p_{90}=15.5 \%$; for GOME-2: $p_{10}=-9.8 \%$, $p_{90}=12.7 \%$.

in Houët and Brogniez (2004), relying on a differential absorption technique (Stamnes et al., 1988). The accuracy of this product is about $3 \%$. We find that this TOC is often larger than OMTO3, which is in agreement with Antón and Loyola (2011) findings for cloud-free conditions (OMTO3 smaller than GB TOC by 2-3\% on average). Figure 5c shows the UVI relative difference between the computed and the GB UVI vs. the TOC relative difference. The computed UVI is often larger than the GB UVI measurements for a negative TOC relative difference, which could explain the positive $1.7 \%$ bias. Note that the denominator of the relative differences (UVI or TOC) is the mean, contrarily to the SB-GB comparisons because, in this study, neither piece of data is considered as a reference.

Another TOC product from OMI (OMDOAO3) exists, which is sometimes quite different from OMTO3 (either larger or smaller) leading to a different modelled UVI and thus to a quite different relative difference. For example, a $7.6 \%$ relative difference between GB UVI (4.8) and modelled UVI using OMTO3 (290 DU) becomes $4.8 \%$ while using OMDOAO3 (297 DU).
TOC from GOME-2 is also sometimes different from OMTO3 and often smaller than spectroradiometer TOC.

Underestimation of OMTO3 and of GOME-2 TOC for cloud-free and cloudy cases, as is found also by Antón and Loyola (2011), can explain part of the observed biases between SB and GB UVI. Aerosol climatology from Kinne (2007) and Kinne et al. (2013) might also contribute to the biases. Indeed, these aerosol climatologies rely on AERONET data that show an interannual variability, and the gridding is $1^{\circ} \times 1^{\circ}$ in latitude-longitude. Cloud cover variability within the satellite pixel (Kazadzis et al., 2009b) is expected to contribute to the biases as well as the surface albedo climatology from Tanskanen (2004).

The impact of the distance between the ground station and the CTP/grid cell centre point appears to be negligible. Tables 3 and 4 report results for distances smaller than or equal to $10 \mathrm{~km}$. For both OMI and GOME-2, the number of UVI pairs (SB-GB) is much smaller than when $100 \mathrm{~km}$ distance is considered. For AS conditions, the correlation between SB UVI and GB UVI data is hardly stronger for both satellite instruments (correlation coefficient increased by 0.01 ). Regression line slopes are closer to 1 than for the $100 \mathrm{~km}$ 
Table 2. Same as Table 1 but for CS conditions.

\begin{tabular}{|c|c|c|c|c|c|c|c|c|c|c|c|c|}
\hline & $n$ & $\begin{array}{r}\text { Mean } \\
\text { bias } \\
\text { UVI }\end{array}$ & $\begin{array}{r}\text { Median } \\
\text { bias } \\
\text { UVI }\end{array}$ & $\begin{array}{r}\text { RMS } \\
\text { UVI }\end{array}$ & $\begin{array}{r}\text { Mean } \\
\text { rel bias } \\
\%\end{array}$ & $\begin{array}{r}\text { Median } \\
\text { rel bias } \\
\%\end{array}$ & $\begin{array}{r}\mathrm{rRMS} \\
\%\end{array}$ & $p_{10}$ & $p_{90}$ & $\begin{array}{l}\text { Slope } \\
\text { (unc.) }\end{array}$ & $\begin{array}{r}\text { Interc. } \\
\text { UVI }\end{array}$ & $r$ \\
\hline \multicolumn{13}{|c|}{ VDA } \\
\hline OMI v1.2/spectro & 72 & 0.71 & 0.79 & 0.84 & 16.8 & 18.1 & 17.8 & 10.0 & 23.3 & $\begin{array}{r}1.20 \\
(0.01)\end{array}$ & -0.08 & 1.00 \\
\hline OMI v1.3/spectro & 72 & 0.32 & 0.32 & 0.40 & 7.9 & 8.4 & 10.2 & 0.0 & 15.5 & $\begin{array}{r}1.10 \\
(0.01)\end{array}$ & -0.06 & 1.00 \\
\hline GOME-2/spectro & 37 & 0.33 & 0.39 & 0.48 & 5.2 & 8.3 & 11.1 & -9.8 & 12.7 & $\begin{array}{r}1.14 \\
(0.02)\end{array}$ & -0.31 & 0.99 \\
\hline \multicolumn{13}{|c|}{ OHP } \\
\hline OMI v1.2/spectro & 266 & 0.88 & 0.90 & 1.03 & 16.3 & 17.2 & 17.4 & 9.2 & 22.7 & $\begin{array}{r}1.18 \\
(0.01)\end{array}$ & -0.05 & 1.00 \\
\hline OMI v1.3/spectro & 263 & 0.26 & 0.24 & 0.42 & 5.5 & 5.8 & 8.9 & -0.7 & $\begin{array}{r}12.1 \\
(0.01)\end{array}$ & 1.05 & 0.01 & 0.99 \\
\hline GOME-2/spectro & 200 & 0.24 & 0.25 & 0.46 & 1.8 & 4.1 & 9.4 & -11.6 & 11.6 & $\begin{array}{r}1.09 \\
(0.01)\end{array}$ & -0.27 & 0.99 \\
\hline \multicolumn{13}{|c|}{ SDR } \\
\hline OMI v1.2/spectro & 175 & 0.29 & 0.44 & 1.10 & 3.6 & 5.0 & 11.2 & -9.9 & 14.8 & $\begin{array}{r}1.02 \\
(0.03)\end{array}$ & 0.01 & 0.94 \\
\hline OMI v1.3/spectro & 170 & 0.30 & 0.37 & 0.87 & 3.5 & 4.2 & 9.4 & -7.9 & 13.7 & $\begin{array}{r}1.03 \\
(0.02)\end{array}$ & 0.00 & 0.96 \\
\hline GOME-2/spectro & 145 & 0.18 & 0.30 & 0.80 & 2.5 & 3.8 & 8.1 & -8.1 & 10.6 & $\begin{array}{r}0.98 \\
(0.02)\end{array}$ & 0.26 & 0.96 \\
\hline
\end{tabular}

case $(1.06 \pm 0.02$ for OMI, $1.10 \pm 0.03$ for GOME-2). However, the relatively large uncertainties limit the significance of these differences. The values of the statistics parameters indicate an agreement close to that obtained for $100 \mathrm{~km}$ (median UVI relative bias for OMI of $10.3 \%$ instead of $12.5 \%$; for GOME-2, $14.3 \%$ instead of $12.1 \%$ ). Based on $p_{90}$ and $p_{10}$ values, the filter on the distance has mainly removed cases of large SB UVI overestimation, not those of SB UVI underestimation $\left(p_{90}<53 \%\right.$, much lower than for $100 \mathrm{~km}$ distance, and $p_{10}$ close to the $100 \mathrm{~km}$ distances).

For CS conditions, correlation between OMI UVI and GB UVI is the same as for $100 \mathrm{~km}$; the slope is almost unchanged $(1.09 \pm 0.01)$; the statistics parameters indicate better agreement (median relative bias $6.6 \%$ instead of $8.4 \%$ ), though these results are statistically less robust than for $100 \mathrm{~km}$ because there are only 14 UVI pairs. As for AS conditions, few cases with large SB overestimation have been removed ( $p_{90}$ about $10 \%, p_{10}$ about $-3 \%$ ). No study can be conducted for GOME-2 (only 2 pairs). Thus, a satellite validation performed with shorter distances between the satellite CTP/grid cell centre point and the GB instrument does not change the results significantly.

Finally, for AS conditions about $56 \%$ of OMI and GOME2 UVI data agree with GB data in the interval [-20, 20\%] (30\% agree in the interval $[-10,10 \%])$. For CS conditions,
$100 \%$ of OMI UVI data and $95 \%$ of GOME-2 UVI data agree with GB data in the interval $[-20,20 \%](60 \%$ agree in the interval $[-10,10 \%])$.

As mentioned above, an additional study compares the performances of the two instruments on common dates. Tables 5 and 6 report the results. For AS conditions, the correlation between SB and GB UVI is strong $(r \sim 0.95)$ for both satellite instruments; the slopes of the regression lines are significantly closer to 1 for OMI $(1.05 \pm 0.01)$ than for GOME-2 (1.12 \pm 0.02$)$, with a negative intercept for GOME-2. For CS conditions, SB and GB UVI measurements are very strongly correlated $(r \sim 0.99)$ for both satellite instruments, the slopes of the regression lines are larger than for AS conditions with a smaller difference between OMI $(1.10 \pm 0.01)$ and GOME-2 $(1.14 \pm 0.02)$. The median biases and median relative biases are very close for both instruments for both AS and CS conditions. OMI and GOME2 overestimations are the same for AS conditions ( $p_{90}$ about $65 \%$ ), but the underestimation is smaller for OMI ( $p_{10}$ about $-11 \%$ for OMI, $-17 \%$ for GOME-2). For CS conditions, OMI essentially overestimates UVI (both $p_{90}$ and $p_{10}$ positive, only $7 \%$ of the cases show a negative relative difference). GOME-2 is unchanged compared to the all-cases study (with underestimation corresponding to a UVI $<3$ ). 

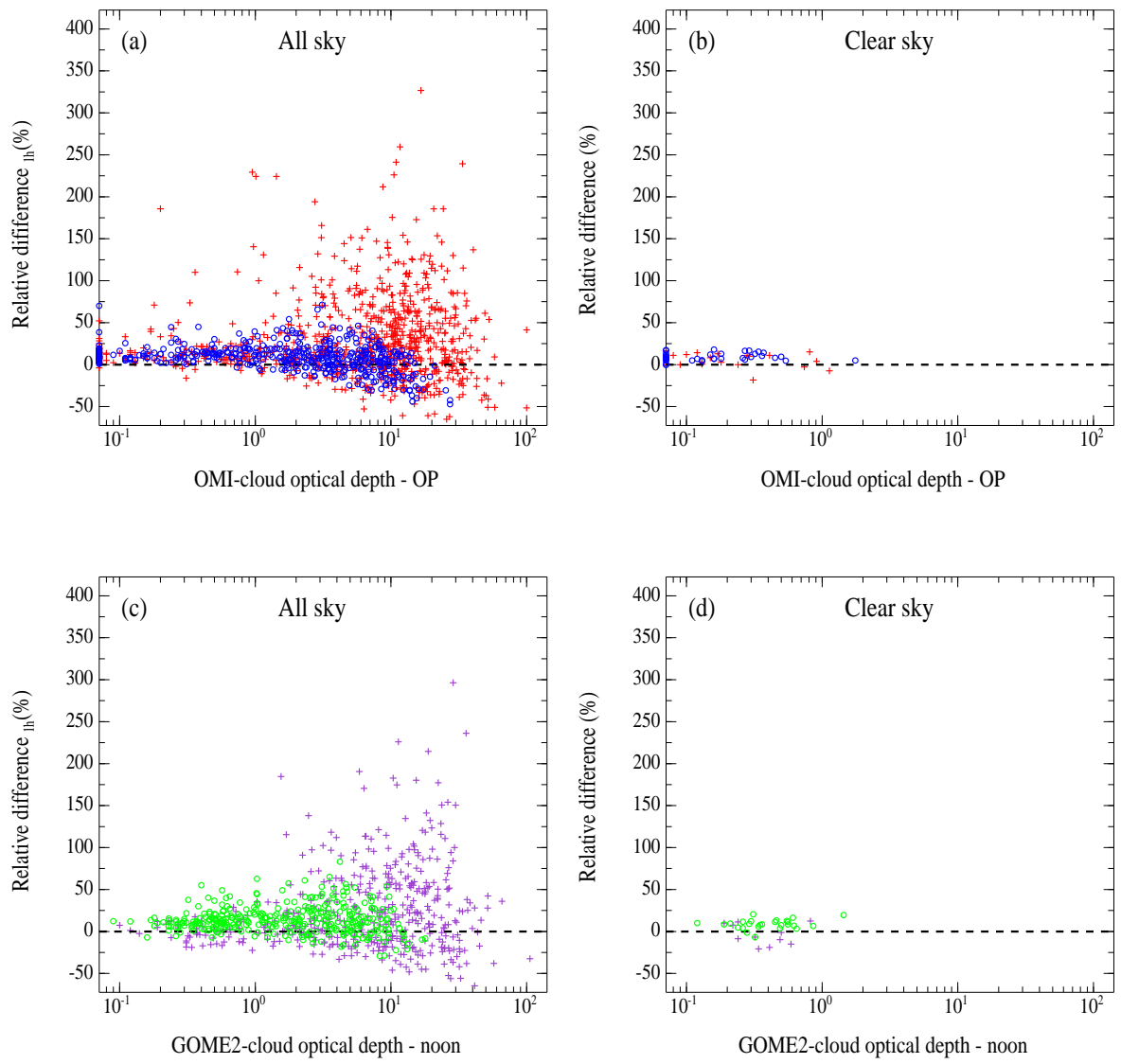

Figure 3. Percent relative difference vs. COD at VDA. COD is given at overpass for OMI v1.3 (top panels) and at noon for GOME-2 (bottom panels). A filtering on the UVI value is made: blue and green circles correspond to UVI (GB value) $\geq 3$. Left plots (a, c) for AS conditions, right plots $(\mathbf{b}, \mathbf{d})$ for CS conditions.

The seasonal variability of differences between SB and GB UVI is greater for GOME-2 with frequently larger values than for OMI outside the winter period. UVI relative differences show no seasonal variability for OMI, but they do for GOME-2 because, as mentioned in the previous study, (i) the UVI differences for GOME-2 are larger than for OMI outside the winter season, leading to larger relative differences for GOME-2 than for OMI, and (ii) there are more negative relative differences for GOME-2 than for OMI, mainly in winter.

Tables 1 and 2 also report the results of the comparison of OMI v1.2 data with GB data. The median UVI relative bias is about $21 \%$ for AS conditions, overestimation is strong and underestimation is weak ( $p_{90}$ about $85 \%, p_{10}$ about $-8 \%$ ). For CS conditions, the median UVI relative bias is about $18 \%$, overestimation is large and there is almost no underestimation ( $p_{90}$ about $23 \%, p_{10}$ about $10 \%$; only $3 \%$ of the cases show a negative relative difference).

Median UVI biases are about 0.4 for AS conditions and about 0.8 for CS conditions. In addition, the slopes of the regression lines are $1.17 \pm 0.01$ for AS conditions and $1.20 \pm$ 0.01 for CS conditions. Apart from the strong correlation between SB and GB UVI (nearly the same as for v1.3), all these statistics parameters are significantly different from those produced by v1.3 and much worse. As expected, v1.3 data are more accurate than v1.2 data. Indeed, as observed in Fig. 6 (red dashed lines), the AOD is quite large (Fig. 6a) and the SSA is significantly smaller than unity (Fig. 6b), leading to a CF applied to v1.2 data to account for absorbing aerosols (see Sect. 2.2.1) much smaller than unity (Fig. 6c). As mentioned previously, UVI relative differences in v1.3 do not exhibit seasonal variability, whereas a weak seasonal variability is observed in v1.2 (not shown), possibly related to CF seasonality. The current validation study at VDA demonstrates that v1.3 offline correction for absorbing aerosol is very efficient, even if there remains a positive bias.

\subsection{OHP}

At this northern midlatitude site, OMI overpasses occur from $0.25 \mathrm{~h}$ before to $2.75 \mathrm{~h}$ after solar noon and GOME- 2 overpasses take place in the morning (ranging from 3.25 to $1 \mathrm{~h}$ before solar noon). The OHP site, located in a mountainous region, is characterized by rather high total ozone columns (on average in the 250-420 DU range) and sometimes by the 

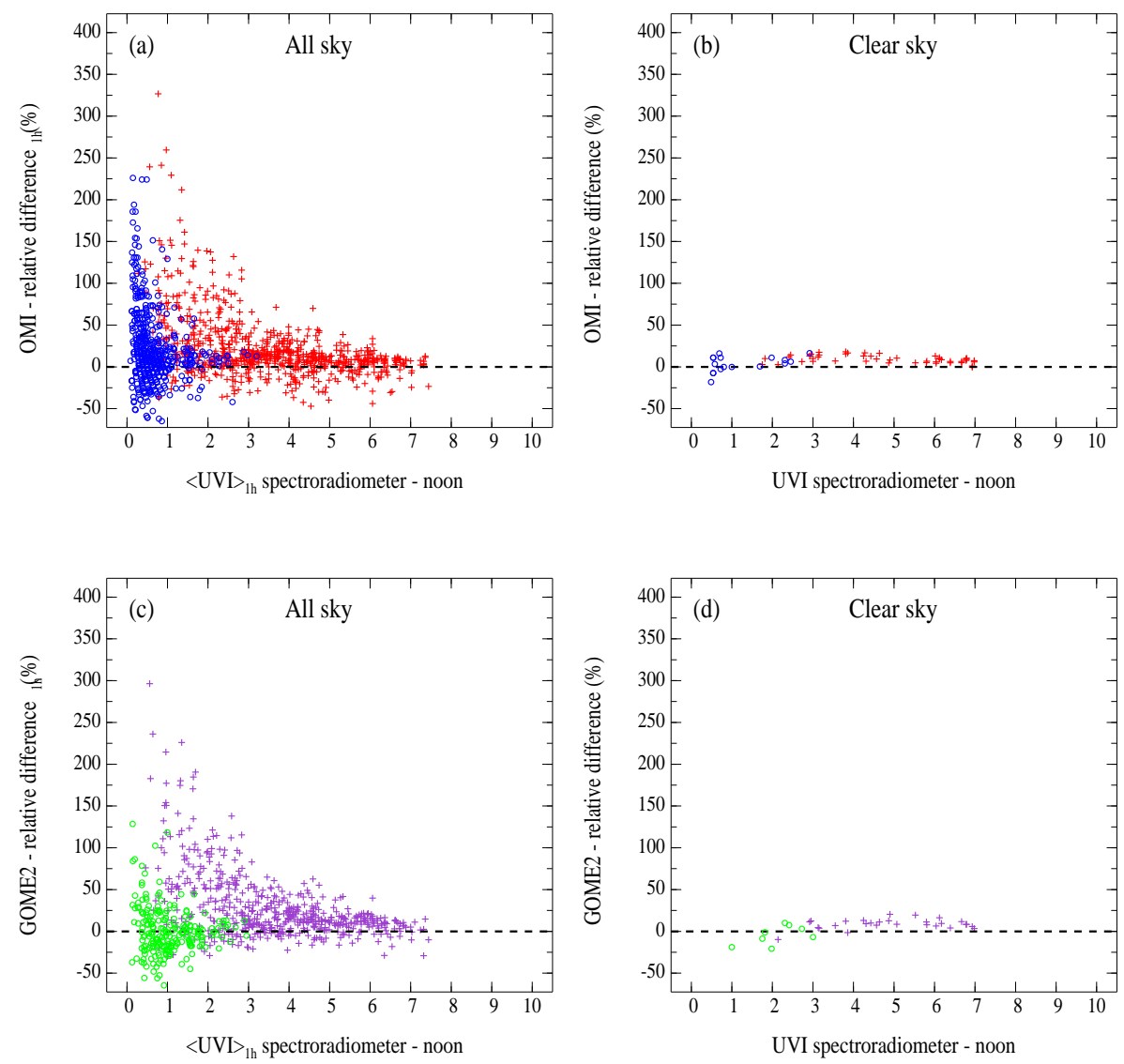

Figure 4. Percent relative difference vs. UVI from GB measurements at VDA for OMI v1.3 (top panels) and GOME-2 (bottom panels). A filtering on SZA at overpass value is set: blue and green circles correspond to SZA $>60^{\circ}$. Left plots (a, c) for AS conditions, right plots (b, d) for CS conditions.

presence of absorbing aerosols. Surface albedo has a weak seasonal variability in the $0.02-0.05$ range.

The first validation is conducted for distance between the GB station and the CTP/grid cell centre point $\leq 100 \mathrm{~km}$.

Results for AS conditions are shown in Fig. 7. Similar to VDA, the GOME-2 data set is limited because only one value per day is available. The data show medium dispersion around relative difference means (SD nearly $50 \%$, means nearly $21 \%$ ), GB and SB UVI are strongly correlated $(r \sim 0.96)$ and regression lines have a slope larger than unity $(1.04 \pm 0.01$ for OMI, $1.05 \pm 0.01$ for GOME-2) with a small intercept. Similar to VDA, satellite-derived UVI is generally larger than GB UVI ( $82 \%$ of positive relative difference for OMI, $72 \%$ for GOME-2). When the COD is smaller than 1 , the relative difference is almost always positive for OMI (Fig. 7b), but is less so for GOME-2 (Fig. 7d). Negative differences for large COD values are observed both for low and high UVI, especially for OMI data. Again, negative differences for small COD values generally correspond to low UVI (Fig. 9a and c) and large SZA, especially for GOME2 (Fig. 10a and c). Median values of the relative biases are about $9.3 \%$ for OMI and $8.4 \%$ for GOME-2. A total of $10 \%$ of the cases correspond to an SB overestimation larger than about $60 \%\left(p_{90}\right)$ for both OMI and GOME-2 (Fig. 7 caption), cases identified as red and violet crosses in Fig. 9a and c, corresponding often to UVI $<3$ and to a large COD, as observed at VDA. A total of $10 \%$ of the cases correspond to an SB underestimation of more than $8 \%$ for OMI and $12 \%$ for GOME-2 $\left(p_{10}\right)$, associated also with UVI $<3$ and with a large COD (Fig. 9c).

Figure 8 shows the results obtained for CS conditions. The dispersion around relative difference means is small (SD $<10 \%$, means $<6 \%$ ), SB and GB UVI are strongly correlated $(r=0.99)$ and the slopes of the regression lines are still larger than unity $(1.05 \pm 0.01$ for OMI, $1.09 \pm 0.01$ for GOME-2). Note that the point well below the regression line in Fig. 8b (red circle) corresponds to an OMI CTP at $98 \mathrm{~km}$ distance from the GB site, $1700 \mathrm{~m}$ a.s.l. and to a large COD (7.75). Satellite-derived UVI is still often larger than GB UVI ( $\sim 85 \%$ of cases for OMI, $68 \%$ for GOME-2). The COD is generally small (Fig. 9b and d), indicating that the satellite algorithms perform a good estimate of the actual cloudiness. As was the case for all sky conditions, GOME-2 UVI is generally smaller than GB UVI for UVI values smaller than 

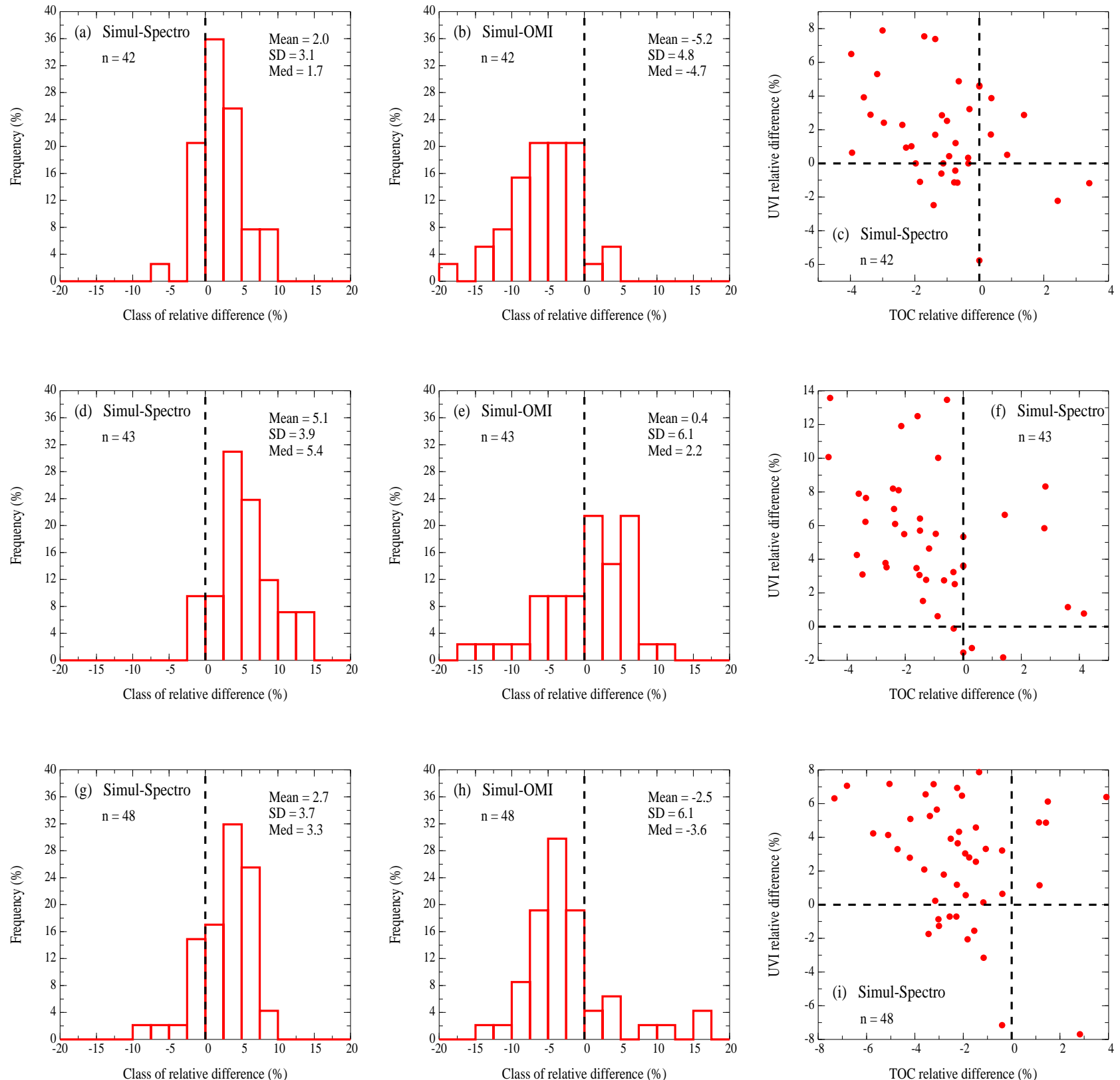

Figure 5. Histograms of the percent relative difference between the simulated and the GB UVI (left panels) and between the simulated and the OMI UVI (middle panels). Relative difference in $\%:$ rdiff $_{i}=200 \times \frac{\text { SIMUL }_{i}-\text { MEAS }_{i}}{\text { SIMUL }_{i}+\text { MEAS }_{i}}$. The right panels show the percent relative difference between the simulated and the GB UVI vs. the TOC relative difference $\left(=200 \times \frac{\text { OMTO }_{i}-\text { TOCspectro }_{i}}{\text { OMTO }_{i}+\text { TOCspectro }_{i}}\right)$. Top panels $(\mathbf{a}, \mathbf{b}, \mathbf{c})$ are for VDA, middle panels $(\mathbf{d}, \mathbf{e}, \mathbf{f})$ for OHP, bottom panels $(\mathbf{g}, \mathbf{h}, \mathbf{i})$ for SDR.

about 3 (green circles); these cases correspond to SZA $>60^{\circ}$ (Fig. 10d). Few such cases are observed for OMI; they correspond to a UVI close to 1 (Fig. 10b). The positive median relative bias is $5.8 \%$ for OMI and $4.1 \%$ for GOME-2. SB overestimation is larger than $12 \%$ for both OMI and GOME-2 in $10 \%$ of the cases ( $p_{90}$, Fig. 8 caption). $p_{10}$ values indicate that $10 \%$ of the cases correspond to an OMI underestimation and more than $12 \%$ to a GOME- 2 underestimation. As previously, for GOME-2 these cases correspond to UVI $<3$ (violet crosses in Fig. 9d).

The statistics of the results are reported in Tables 1 and 2 . The median bias is positive and small for both satellite instruments: 0.32 for OMI and 0.41 for GOME- 2 for AS conditions, and about 0.25 for both OMI and GOME-2 for CS conditions. 
Table 3. Same as Table 1 but with a filter on the distance between the station and the CTP/grid cell centre point (distance $\leq 10 \mathrm{~km}$ ), and with a filter on OMI CTP altitude. Dist indicates distance and Alti indicates altitude. At OHP, the altitude filter is site altitude $-250 \mathrm{~m} \leq \mathrm{CTP}$ altitude $\leq$ site altitude $+250 \mathrm{~m}$. At SDR, the altitude filter is $0 \mathrm{~m} \leq \mathrm{CTP}$ altitude $\leq$ site altitude $+250 \mathrm{~m}$.

\begin{tabular}{|c|c|c|c|c|c|c|c|c|c|c|c|c|}
\hline & $n$ & $\begin{array}{r}\text { Mean } \\
\text { bias } \\
\text { UVI }\end{array}$ & $\begin{array}{r}\text { Median } \\
\text { bias } \\
\text { UVI }\end{array}$ & $\begin{array}{c}\text { RMS } \\
\text { UVI }\end{array}$ & $\begin{array}{r}\text { Mean } \\
\text { rel bias } \\
\%\end{array}$ & $\begin{array}{r}\text { Median } \\
\text { rel bias } \\
\%\end{array}$ & $\begin{array}{r}\text { rRMS } \\
\%\end{array}$ & $p_{10}$ & $p_{90}$ & $\begin{array}{l}\text { Slope } \\
\text { (unc.) }\end{array}$ & $\begin{array}{r}\text { Interc. } \\
\text { UVI }\end{array}$ & $r$ \\
\hline \multicolumn{13}{|c|}{ VDA } \\
\hline Dist OMI v1.3/spectro & 349 & 0.25 & 0.16 & 0.61 & 15.4 & 10.3 & 34.8 & -15.4 & 50.0 & $\begin{array}{r}1.06 \\
(0.02)\end{array}$ & -0.01 & 0.96 \\
\hline Dist GOME-2/spectro & 114 & 0.43 & 0.28 & 0.79 & 15.8 & 14.3 & 31.0 & -13.7 & 52.4 & $\begin{array}{r}1.10 \\
(0.03)\end{array}$ & -0.05 & 0.95 \\
\hline \multicolumn{13}{|c|}{$\mathrm{OHP}$} \\
\hline Dist OMI v1.3/spectro & 273 & 0.42 & 0.34 & 0.76 & 19.2 & 8.3 & 46.2 & -3.2 & 44.8 & $\begin{array}{r}1.05 \\
(0.02)\end{array}$ & 0.06 & 0.97 \\
\hline Alti OMI v1.3/spectro & 687 & 0.42 & 0.32 & 0.78 & 21.9 & 9.3 & 54.7 & -6.0 & 53.2 & $\begin{array}{r}1.05 \\
(0.01)\end{array}$ & 0.07 & 0.97 \\
\hline Dist GOME-2/spectro & 144 & 0.60 & 0.49 & 1.12 & 22.2 & 10.3 & 54.3 & -14.0 & 59.7 & $\begin{array}{r}0.99 \\
(0.03)\end{array}$ & 0.09 & 0.95 \\
\hline \multicolumn{13}{|c|}{ SDR } \\
\hline Dist OMI v1.3/spectro & 341 & 1.06 & 0.60 & 2.41 & 21.5 & 8.1 & 52.7 & -12.6 & 67.1 & $\begin{array}{r}0.91 \\
(0.03)\end{array}$ & 1.10 & 0.75 \\
\hline Alti OMI v1.3/spectro & 576 & 1.56 & 0.94 & 2.83 & 32.0 & 11.9 & 68.3 & -6.4 & 93.5 & $\begin{array}{r}0.92 \\
(0.03)\end{array}$ & 1.45 & 0.74 \\
\hline Dist GOME-2/spectro & 93 & 1.73 & 1.00 & 3.17 & 40.2 & 11.0 & 91.5 & -7.7 & 114.4 & $\begin{array}{r}0.62 \\
(0.09)\end{array}$ & 3.67 & 0.60 \\
\hline
\end{tabular}

Table 4. Same as Table 3 but for CS conditions.

\begin{tabular}{|c|c|c|c|c|c|c|c|c|c|c|c|c|}
\hline & $n$ & $\begin{array}{r}\text { Mean } \\
\text { bias } \\
\text { UVI }\end{array}$ & $\begin{array}{r}\text { Median } \\
\text { bias } \\
\text { UVI }\end{array}$ & $\begin{array}{r}\text { RMS } \\
\text { UVI }\end{array}$ & $\begin{array}{r}\text { Mean } \\
\text { rel bias } \\
\%\end{array}$ & $\begin{array}{r}\text { Median } \\
\text { rel bias } \\
\%\end{array}$ & $\begin{array}{r}\text { rRMS } \\
\%\end{array}$ & $p_{10}$ & $p_{90}$ & $\begin{array}{l}\text { Slope } \\
\text { (unc.) }\end{array}$ & $\begin{array}{r}\text { Interc. } \\
\text { UVI }\end{array}$ & $r$ \\
\hline \multicolumn{13}{|c|}{ VDA } \\
\hline Dist OMI v1.3/spectro & 14 & 0.28 & 0.32 & 0.36 & 5.4 & 6.6 & 8.0 & -2.8 & 9.5 & $\begin{array}{r}1.09 \\
(0.01)\end{array}$ & -0.08 & 1.00 \\
\hline Dist GOME-2/spectro & 2 & & & & & & & & & & & \\
\hline \multicolumn{13}{|c|}{$\mathrm{OHP}$} \\
\hline Dist OMI v1.3/spectro & 53 & 0.29 & 0.25 & 0.41 & 5.2 & 5.3 & 8.6 & -0.4 & 11.1 & $\begin{array}{r}1.07 \\
(0.02)\end{array}$ & -0.09 & 0.99 \\
\hline Alti OMI v1.3/spectro & 145 & 0.29 & 0.24 & 0.40 & 5.8 & 5.9 & 8.3 & -0.4 & 12.0 & $\begin{array}{r}1.05 \\
(0.01)\end{array}$ & 0.00 & 1.00 \\
\hline Dist GOME-2/spectro & 19 & 0.23 & 0.18 & 0.53 & 0.3 & 4.5 & 11.0 & -19.3 & 8.8 & $\begin{array}{r}1.11 \\
(0.03)\end{array}$ & -0.33 & 0.99 \\
\hline \multicolumn{13}{|c|}{ SDR } \\
\hline Dist OMI v1.3/spectro & 89 & 0.13 & 0.28 & 0.89 & 1.8 & 3.8 & 9.4 & -13.1 & 10.7 & $\begin{array}{r}1.00 \\
(0.04)\end{array}$ & 0.06 & 0.96 \\
\hline Alti OMI v1.3/spectro & 119 & 0.41 & 0.45 & 0.82 & 4.7 & 5.5 & 9.1 & -4.1 & 14.0 & $\begin{array}{r}1.05 \\
(0.03)\end{array}$ & -0.06 & 0.98 \\
\hline Dist GOME-2/spectro & 16 & 0.01 & 0.23 & 0.89 & 1.3 & 3.2 & 8.0 & -10.2 & 6.0 & $\begin{array}{r}0.90 \\
(0.07)\end{array}$ & 0.88 & 0.96 \\
\hline
\end{tabular}


Table 5. Same as Table 1 but for the same dates for both OMI and GOME-2.

\begin{tabular}{|c|c|c|c|c|c|c|c|c|c|c|c|c|}
\hline & $n$ & $\begin{array}{r}\text { Mean } \\
\text { bias } \\
\text { UVI }\end{array}$ & $\begin{array}{r}\text { Median } \\
\text { bias } \\
\text { UVI }\end{array}$ & $\begin{array}{r}\text { RMS } \\
\text { UVI }\end{array}$ & $\begin{array}{r}\text { Mean } \\
\text { rel bias } \\
\%\end{array}$ & $\begin{array}{r}\text { Median } \\
\text { rel bias } \\
\%\end{array}$ & $\begin{array}{r}\text { rRMS } \\
\%\end{array}$ & $p_{10}$ & $p_{90}$ & $\begin{array}{l}\text { Slope } \\
\text { (unc.) }\end{array}$ & $\begin{array}{c}\text { Interc. } \\
\text { UVI }\end{array}$ & $r$ \\
\hline \multicolumn{13}{|c|}{ VDA } \\
\hline OMI v1.3/spectro & 681 & 0.37 & 0.29 & 0.72 & 21.2 & 12.1 & 41.8 & -10.6 & 65.5 & $\begin{array}{r}1.05 \\
(0.01)\end{array}$ & 0.08 & 0.95 \\
\hline GOME-2/spectro & 681 & 0.50 & 0.32 & 0.89 & 20.2 & 12.1 & 44.6 & -16.9 & 64.9 & $\begin{array}{r}1.12 \\
(0.02)\end{array}$ & -0.12 & 0.94 \\
\hline \multicolumn{13}{|c|}{$\mathrm{OHP}$} \\
\hline OMI v1.3/spectro & 821 & 0.39 & 0.30 & 0.83 & 20.5 & 8.5 & 51.9 & -8.0 & 55.9 & $\begin{array}{r}1.04 \\
(0.01)\end{array}$ & 0.08 & 0.96 \\
\hline GOME-2/spectro & 821 & 0.54 & 0.43 & 0.97 & 19.1 & 8.4 & 50.6 & -11.7 & 52.9 & $\begin{array}{r}1.06 \\
(0.01)\end{array}$ & -0.06 & 0.96 \\
\hline \multicolumn{13}{|c|}{ SDR } \\
\hline OMI v1.3/spectro & 523 & 1.34 & 0.75 & 2.66 & 29.2 & 10.1 & 66.7 & -10.4 & 81.2 & $\begin{array}{r}0.91 \\
(0.03)\end{array}$ & 1.28 & 0.74 \\
\hline GOME-2/spectro & 523 & 1.58 & 0.90 & 2.84 & 35.1 & 11.3 & 75.5 & -6.4 & 104.1 & $\begin{array}{r}0.78 \\
(0.03)\end{array}$ & 2.40 & 0.70 \\
\hline
\end{tabular}

Table 6. Same as Table 2 but for the same dates for both OMI and GOME-2.

\begin{tabular}{|c|c|c|c|c|c|c|c|c|c|c|c|c|}
\hline & $n$ & $\begin{array}{r}\text { Mean } \\
\text { bias } \\
\text { UVI }\end{array}$ & $\begin{array}{r}\text { Median } \\
\text { bias } \\
\text { UVI }\end{array}$ & $\begin{array}{r}\text { RMS } \\
\text { UVI }\end{array}$ & $\begin{array}{r}\text { Mean } \\
\text { rel bias } \\
\%\end{array}$ & $\begin{array}{r}\text { Median } \\
\text { rel bias } \\
\%\end{array}$ & $\begin{array}{r}\text { rRMS } \\
\%\end{array}$ & $p_{10}$ & $p_{90}$ & $\begin{array}{l}\text { Slope } \\
\text { (unc.) }\end{array}$ & $\begin{array}{r}\text { Interc. } \\
\text { UVI }\end{array}$ & $r$ \\
\hline \multicolumn{13}{|c|}{ VDA } \\
\hline OMI v1.3/spectro & 37 & 0.36 & 0.37 & 0.41 & 8.5 & 8.6 & 9.8 & 2.8 & 15.2 & $\begin{array}{r}1.10 \\
(0.01)\end{array}$ & -0.07 & 1.00 \\
\hline GOME-2/spectro & 37 & 0.33 & 0.39 & 0.48 & 5.2 & 8.3 & 11.1 & -9.8 & 12.7 & $\begin{array}{r}1.14 \\
(0.02)\end{array}$ & -0.31 & 0.99 \\
\hline \multicolumn{13}{|c|}{ OHP } \\
\hline OMI v1.3/spectro & 168 & 0.27 & 0.23 & 0.38 & 5.5 & 5.4 & 8.6 & -0.5 & 11.9 & $\begin{array}{r}1.05 \\
(0.01)\end{array}$ & -0.01 & 0.99 \\
\hline GOME-2/spectro & 168 & 0.26 & 0.27 & 0.47 & 2.2 & 4.3 & 9.5 & -11.4 & 11.6 & $\begin{array}{r}1.09 \\
(0.01)\end{array}$ & -0.27 & 0.99 \\
\hline \multicolumn{13}{|c|}{ SDR } \\
\hline OMI v1.3/spectro & 115 & 0.29 & 0.35 & 0.91 & 3.6 & 4.3 & 9.8 & -7.9 & 13.9 & $\begin{array}{r}1.02 \\
(0.03)\end{array}$ & 0.06 & 0.96 \\
\hline GOME-2/spectro & 115 & 0.14 & 0.24 & 0.84 & 2.2 & 3.4 & 8.4 & -9.0 & 11.6 & $\begin{array}{r}0.97 \\
(0.03)\end{array}$ & 0.34 & 0.96 \\
\hline
\end{tabular}

As for VDA, seasonal variability is observed with differences for both satellite instruments with smaller values in winter. OMI relative differences show no seasonal variability, but GOME-2 relative differences exhibit seasonal variations not explained by the observed weak surface albedo seasonality.
Both satellite overpass times can be quite different from noon, however, no correlation between the relative difference and the time difference is observed (not shown).

As for VDA, we have performed RT calculations also with midlatitude ozone, temperature and pressure profiles. Figure $5 \mathrm{~d}$ and e show the histograms of the percent relative difference between the computed UVI and the measured one for cloud-free conditions. GB and OMI UVI are 5.4 and $2.2 \%$ 

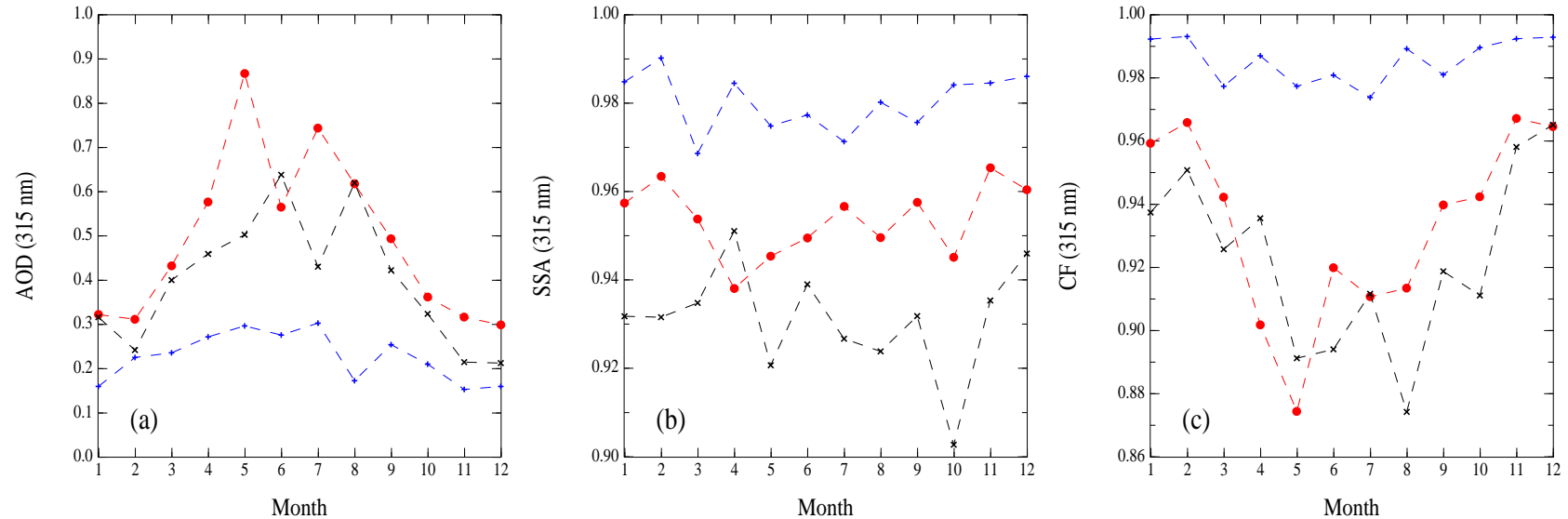

Figure 6. Aerosol data at $315 \mathrm{~nm}$ used in the OMI v1.3 correction for absorbing aerosols. (a) AOD; (b) SSA; (c) correction factor. Red curves are for VDA, black curves are for OHP and blue curves are for SDR.
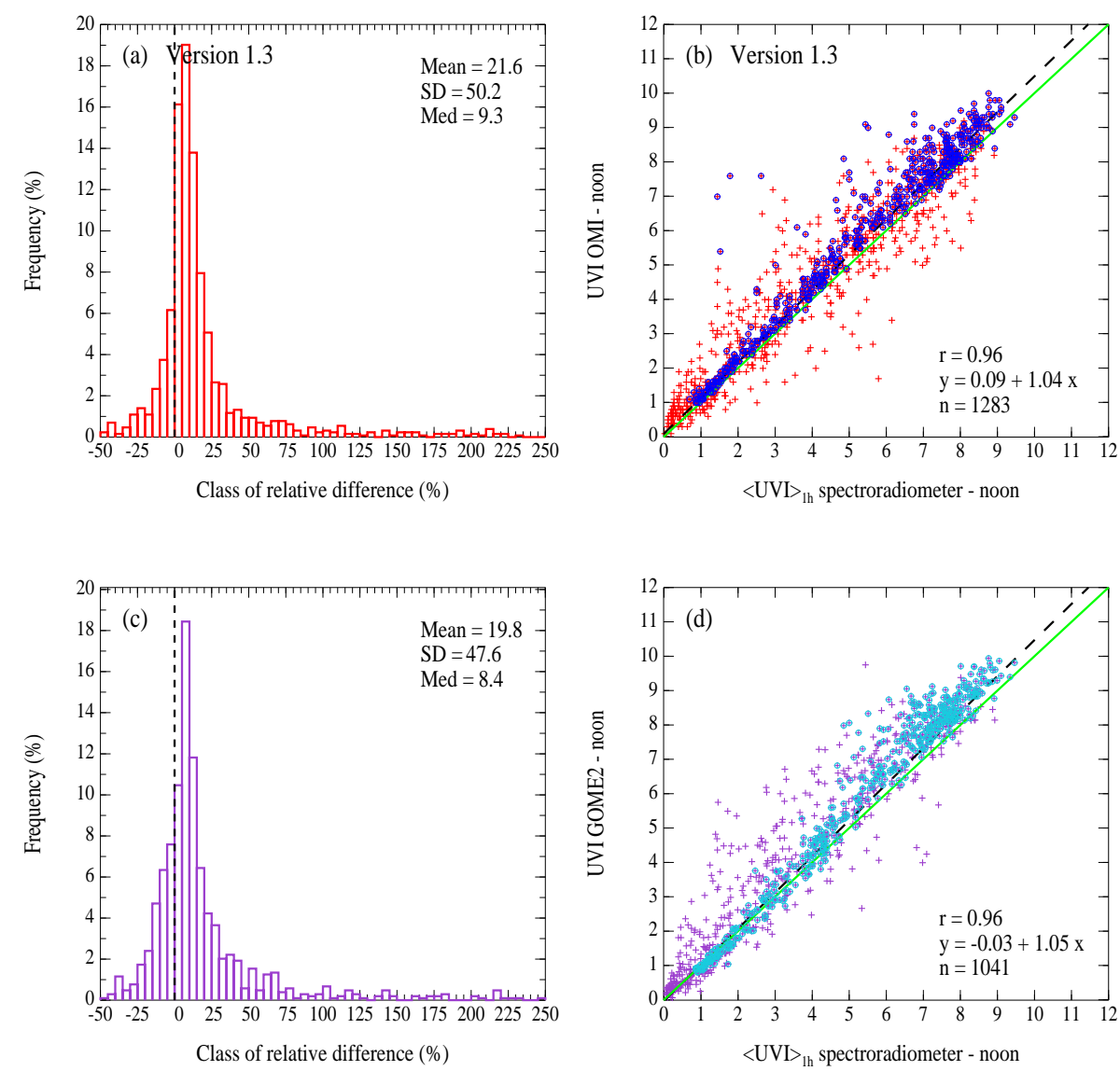

Figure 7. Same as Fig. 1 but for OHP. Percentiles for OMI: $p_{10}=-8.0 \%, p_{90}=57.4 \%$; for GOME-2: $p_{10}=-11.9 \%, p_{90}=60.3 \%$.

smaller than the simulated UVI, respectively. This small underestimation of OMI UVI is well within OMI measurement uncertainty and is caused, as at VDA, by differences between the input parameters (aerosol parameters, surface albedo, etc.) and between the two RT models used. Though rather large, the underestimation of GB UVI is still consistent with
GB measurement uncertainty. This bias is explained considering the TOC value. Indeed, as at VDA, the TOC derived from the GB spectra is often larger than OMTO3. Figure $5 \mathrm{f}$ shows the UVI relative difference between the computed and the GB UVI vs. the TOC relative difference. The modelled 

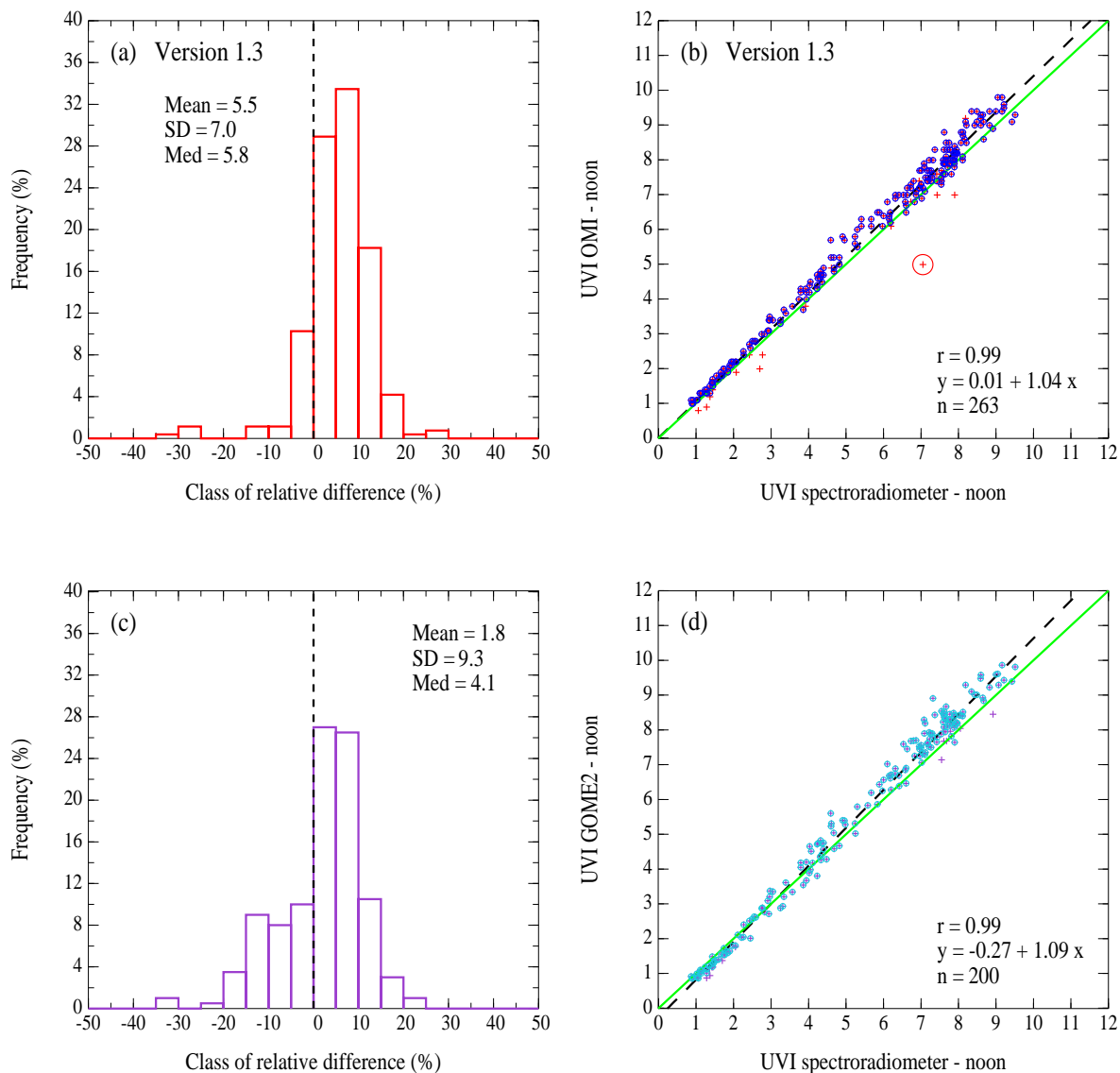

Figure 8. Same as Fig. 2 but for OHP. Percentiles for OMI: $p_{10}=-0.7 \%, p_{90}=12.1 \%$; for GOME-2: $p_{10}=-11.6 \%, p_{90}=11.6 \%$.

UVI is larger than the GB UVI for a negative TOC relative difference, which is consistent with the $5.4 \%$ bias.

Similar to VDA, TOC from GOME-2 is also sometimes different from OMTO3, and often smaller than spectroradiometer TOC (in agreement with Antón and Loyola (2011). Thus, part of the observed positive biases between SB and GB UVI for cloud-free and cloudy conditions can be explained by OMTO3 and GOME-2 TOC underestimation. At this site also, cloud cover variability within the satellite pixel (Kazadzis et al., 2009b), aerosol climatology (Kinne et al., 2013) and surface albedo climatology (Tanskanen, 2004) might explain part of the biases.

The results for distances between the ground station and the CTP/grid cell centre point $\leq 10 \mathrm{~km}$ are reported in Tables 3 and 4 . The number of events is much smaller than for the $100 \mathrm{~km}$ distance. For AS conditions, the slope of the regression line for OMI data is nearly unchanged compared to the $100 \mathrm{~km}$ distance case $(1.05 \pm 0.02)$, and the correlation coefficient and the parameters (median bias and median relative bias) are nearly unchanged as well. For GOME-2, though the slope of the regression line is closer to 1 compared to $100 \mathrm{~km}$ distance and the correlation coefficient is nearly unchanged, the statistics parameters are slightly worse. $p_{90}$ is much smaller for OMI (45\%), and unchanged for GOME2 compared to that for $100 \mathrm{~km}$ distance, and $p_{10}$ is close to the $100 \mathrm{~km}$ distances. That means that the filter on the distance has mainly removed cases of large OMI UVI overestimations.

For CS conditions, for both OMI and GOME-2, the regression slopes are not significantly different from those for $100 \mathrm{~km}$ distance, and the statistics of the results are very similar, with the exception of the GOME- $2 p_{10}$ percentile $(-19 \%)$ meaning that the underestimation is stronger, though GOME-2 results are statistically less robust than for $100 \mathrm{~km}$ because there are only 19 UVI pairs. Thus, the distance between the satellite CTP/grid cell centre point and the GB instrument does not significantly affect the results of the satellite sensor validation.

Since the region is mountainous, the effect of altitude may be evident in the data. The influence of altitude can only be studied with OMI data for which the terrain height is available in the OMUVB files. Tables 3 and 4 report the results accounting for CTP whose altitude is within $\pm 250 \mathrm{~m}$ from the ground site altitude, with this value being chosen as leading only to a $\pm 2-3 \%$ shift in erythemally weighted UV (McKenzie et al., 2001). Whether for AS or for CS conditions, the 

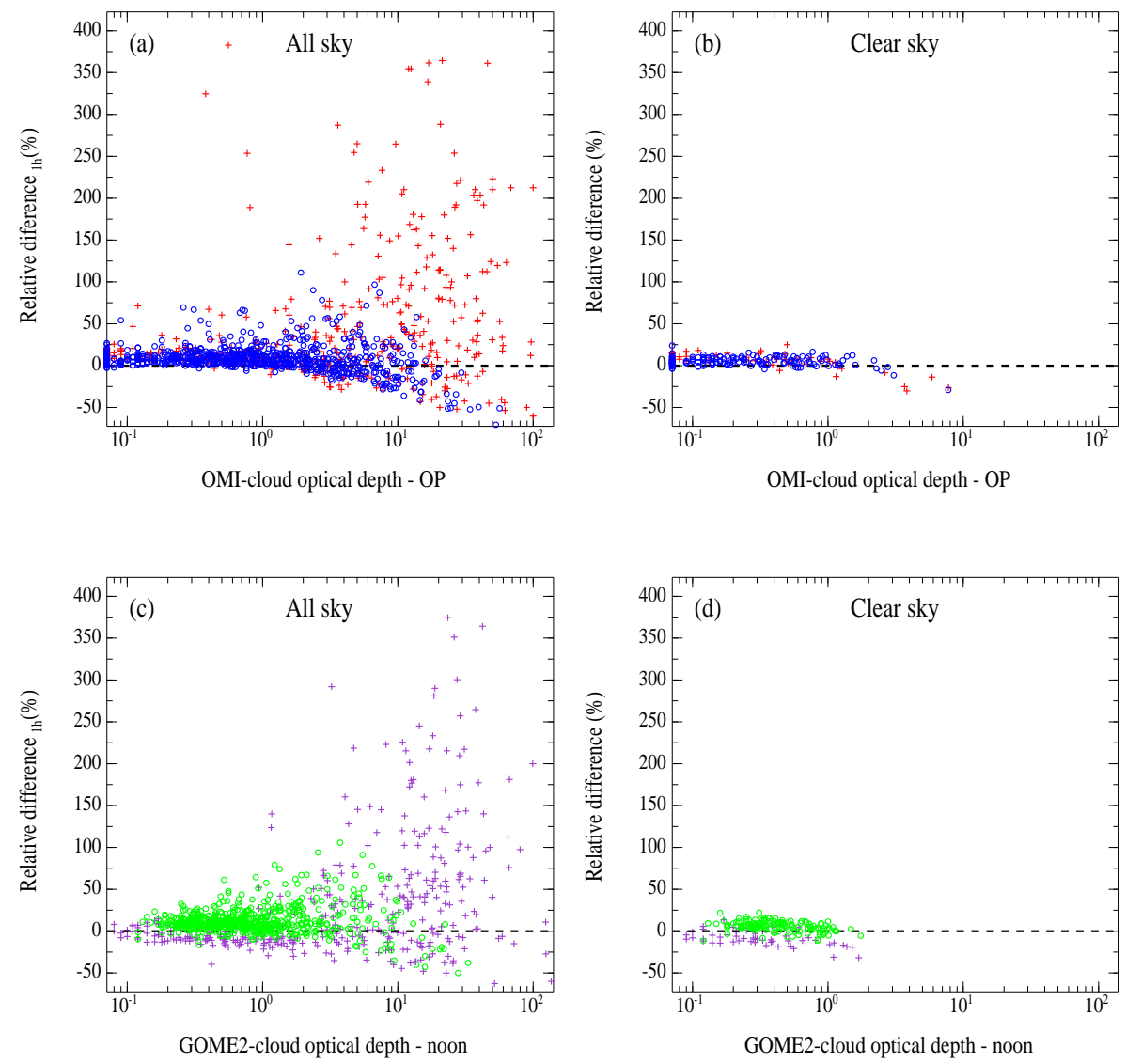

Figure 9. Same as Fig. 3 but for OHP.

statistics parameters (as well as the regression line slope and correlation coefficient) are very close to those obtained without a filter on altitude. So, the altitude selection does not improve the comparisons between SB and GB data. This is likely due to OMI-estimated cloudiness, OMI spatial resolution and also the fact that CTPs with lower and higher altitude compared to the actual altitude of the site give opposite effects on UVI. Indeed, all these factors play a role in the validations carried out with or without an altitude selection.

Finally, for AS conditions, about $70 \%$ of OMI UVI data and about $67 \%$ of GOME-2 data agree with GB data in the interval $[-20,20 \%](44 \%$ agree in $[-10,10 \%])$. For CS conditions, about $97 \%$ of both OMI and GOME-2 UVI data agree with GB data in the interval $[-20,20 \%]$ (72\% agree in $[-10,10 \%])$.

The statistical comparisons restricted to the same dates for both OMI and GOME-2 are reported in Tables 5 and 6. For AS conditions, the correlation between SB and GB UVI data is strong $(r \sim 0.96)$ for both satellite instruments, and the slopes of the regression lines are larger than 1, with no significant difference. For CS conditions, the correlation is very strong $(r \sim 0.99)$, the regression slope for OMI is slightly closer to 1 than for GOME-2. For AS conditions, median relative biases between GB and SB UVI data are very close for
OMI and GOME-2, but median absolute bias for GOME-2 is larger than for OMI. For CS conditions, the median relative bias for GOME-2 is smaller than for OMI but median absolute bias for GOME-2 is larger than for OMI. This different behaviour between median relative bias and median bias for OMI and for GOME- 2 is due to the seasonality of the relative differences and differences for GOME-2 - GB UVI pairs. Indeed, the seasonal variability of differences between SB and GB UVI is greater for GOME-2 than for OMI, and, as observed for VDA, OMI relative differences between SB and GB UVI show no seasonal variability, but GOME-2 relative differences do. OMI and GOME-2 overestimations are very close for AS conditions ( $p_{90}$ about $55 \%$ ), and the underestimation is smaller for OMI ( $p_{10}$ about $-8 \%$ for OMI, $-12 \%$ for GOME-2). For CS conditions, OMI mainly overestimates UVI ( $\left.p_{10}=-0.5 \%\right)$, and the GOME- 2 underestimation is much larger ( $p_{10}$ about $\left.-11 \%\right)$.

The statistics of the results of the comparison for OMI v1.2 are also reported in Tables 1 and 2. The median relative bias is about $20 \%$ for AS conditions; v1.2 strongly overestimates and weakly underestimates UVI ( $p_{90}$ about $73 \%, p_{10}$ about $2 \%$ ). For CS conditions, the median UVI relative bias is about $17 \%$, overestimation is large and there is almost no 

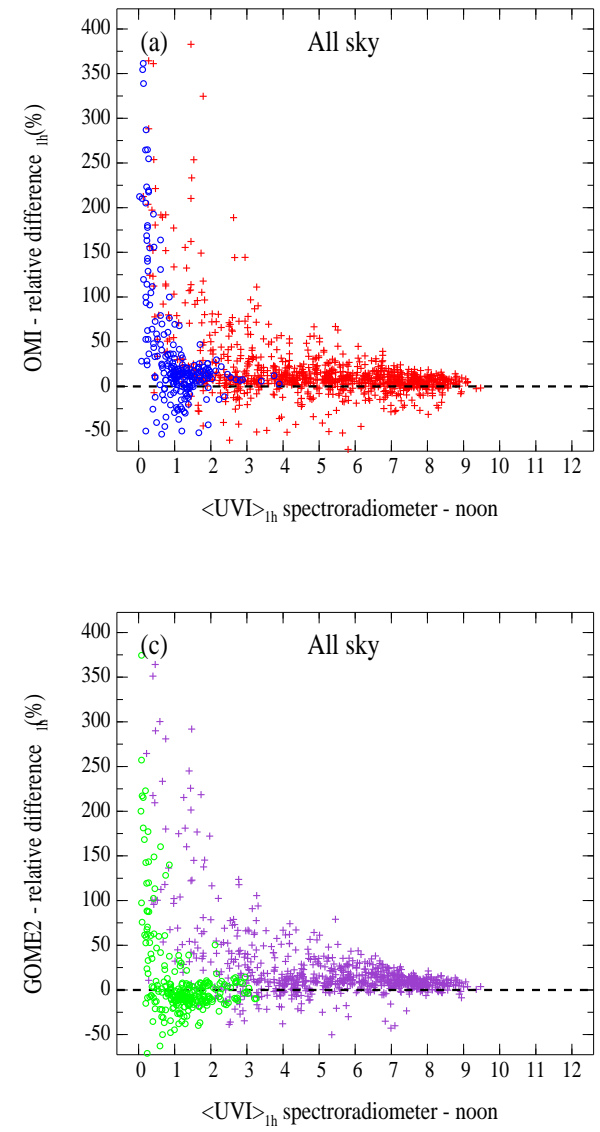

Figure 10. Same as Fig. 4 but for OHP.

underestimation ( $p_{90}$ about $23 \%, p_{10}$ about $9 \% ; 3 \%$ of the cases show a negative relative difference).

Median biases are about 0.8 for AS conditions and about 0.9 for CS conditions. The slopes of the regression lines are $1.14 \pm 0.01$ for AS conditions and $1.18 \pm 0.01$ for CS conditions. Thus, all these statistics parameters are significantly larger than those produced by v1.3, indicating that v1.3 product is more reliable than v1.2. This result can be understood by looking at Fig. 6 (black dashed lines). AOD is quite large (Fig. 6a) and SSA is significantly smaller than unity (Fig. 6b), leading to a CF applied to v1.2 UVI that is much lower than unity (Fig. 6c). The current validation study at OHP shows that the correction for absorbing aerosol performed in v1.3 is very efficient, though imperfect.

\subsection{SDR}

In the tropical region, OMI overpasses occur in the afternoon from 0.75 to $3.5 \mathrm{~h}$ after solar noon and GOME- 2 in the morning from 4.25 to $2.25 \mathrm{~h}$ before solar noon. As mentioned previously, SDR is characterized by rather low total ozone column (on average in the 240-300 DU range), by the proximity to the ocean, by a complex topography and by a frequent occurrence of clouds forming at around midday. Cloud vari-
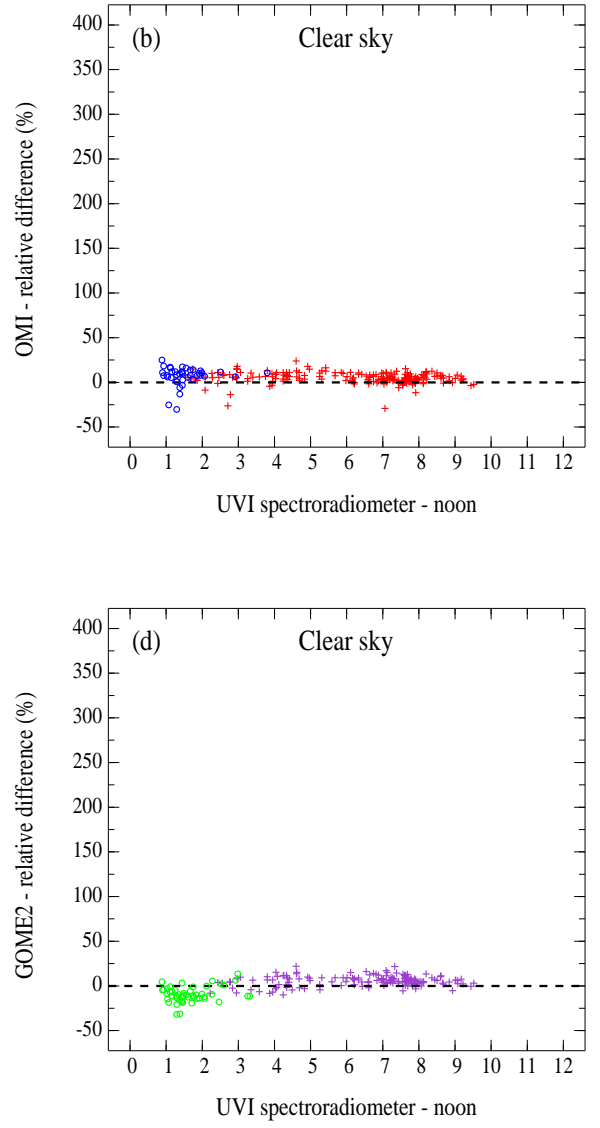

ability between overpass time and noon is thus high, cloud sub-pixel variation is also high, and therefore, cloudiness estimation is the most important factor of uncertainty in deriving UVI from space measurements. This site may be not representative of satellite pixels because a large part of the area contributing to the satellite measurement is over the ocean where the cloud cover is likely different from that over the mountainous island. As at the other sites, surface albedo has a weak seasonality in the $0.04-0.08$ range.

The first validation is conducted for distance between the GB station and the CTP/grid cell centre point $\leq 100 \mathrm{~km}$.

Results for AS conditions are shown in Fig. 11. Similar to other sites, the GOME-2 data set is limited because only one value per day is available. The data show large dispersion around relative difference means (SD nearly $57 \%$, mean nearly $29 \%$ for OMI and SD nearly $67 \%$; mean nearly $35 \%$ for GOME-2.). These dispersions and means are larger than at the two other sites. GB and SB UVI are correlated less strongly than at other sites $(r \sim 0.74$ for OMI, $r \sim 0.71$ for GOME-2), though the correlation is significant since the probability of getting these $r$ values by chance is lower than $0.05 \%$. The slopes of the regression lines are much smaller than unity $(0.91 \pm 0.02$ for OMI, $0.78 \pm 0.03$ for GOME2). Satellite-derived UVI is generally larger than GB UVI 

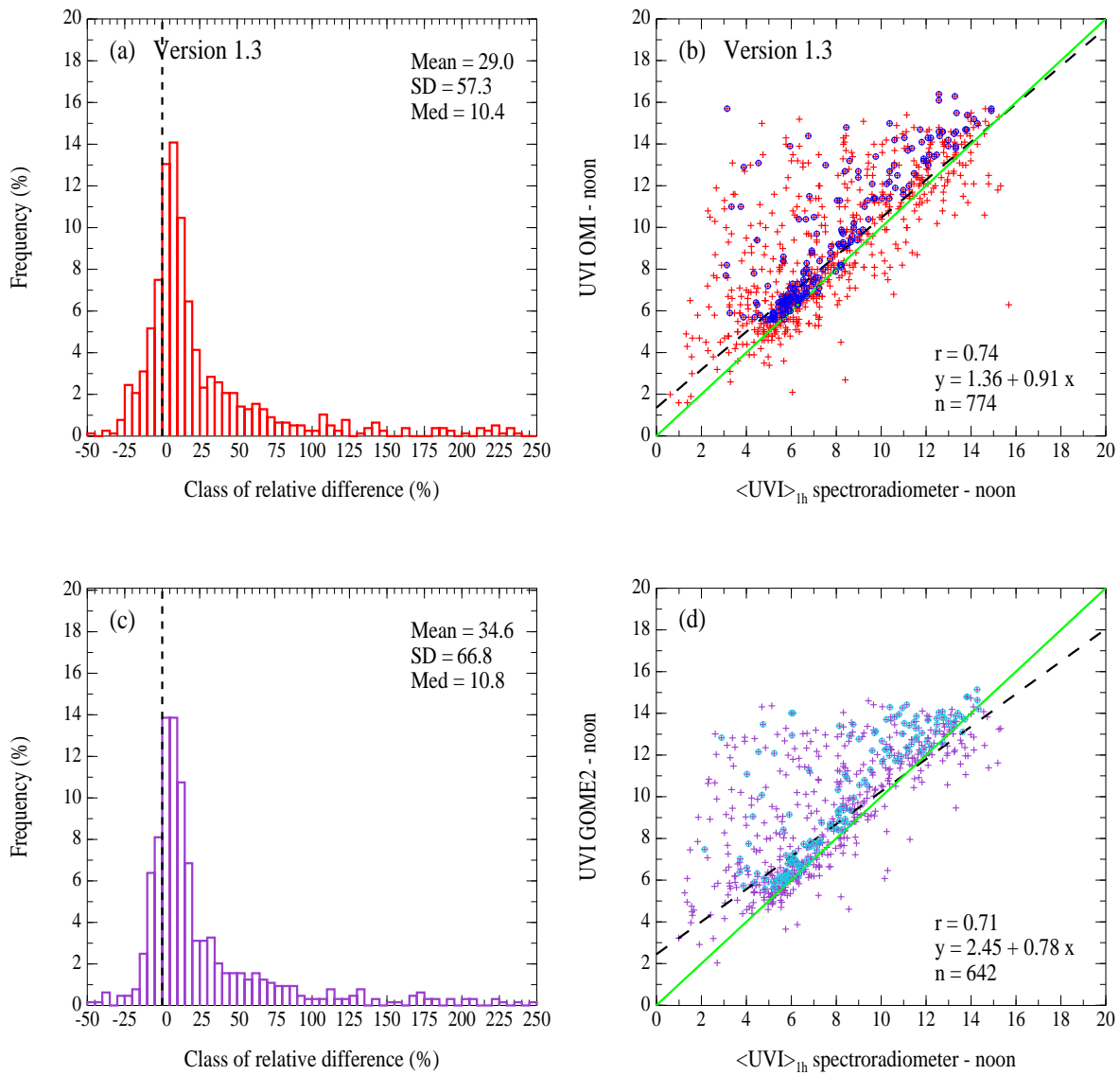

Figure 11. Same as Fig. 1 but for SDR. Percentiles for OMI: $p_{10}=-9.2 \%, p_{90}=85.9 \%$; for GOME-2: $p_{10}=-6.0 \%, p_{90}=99.9 \%$.

( $\sim 80 \%$ of positive relative difference for both OMI and GOME-2). When the COD is smaller than 1, the relative difference is almost always positive for both instruments (Fig. 11b and d). Satellite-derived UVI smaller than GB UVI can occur when the COD is large, as seen in Fig. 13a and c. No link with SZA at overpass is observed; indeed, for OMI observations, SZA is almost always smaller than $60^{\circ}$, and for GOME-2 several cases with SZA at overpass $>60^{\circ}$ occur but the relative differences are not more negative than for other cases (not shown).

Median values of the relative biases are about $10 \%$ for both OMI and GOME-2. The $p_{90}$ values indicate that $10 \%$ of the cases correspond to an SB overestimation larger than about $86 \%$ for OMI and $100 \%$ for GOME-2 (Fig. 11 caption); these values are much larger than those observed at VDA and OHP. A total of $10 \%\left(p_{10}\right)$ of the cases correspond to an SB underestimation of more than about $9 \%$ for OMI and $6 \%$ for GOME- 2 .

Figure 12 shows the results obtained for CS conditions. The dispersion around relative difference means is much lower than for AS conditions ( $\mathrm{SD}<9 \%$, means $<4 \%$ ), the correlations between SB and GB UVI are high, though weaker than at the two other sites $(r=0.96)$ and the slopes of the regression lines are close to unity $(1.03 \pm 0.02$ for OMI, $0.98 \pm 0.02$ for GOME-2). Several SB-GB UVI pairs show negative relative differences, which correspond to COD $>1$. As seen in Fig. 13b and d, the COD can still be large, indicating the difficulty for both satellite algorithms to estimate the actual cloudiness (i.e. no clouds here), though the possibility of a bad selection of CS cases at the GB site cannot be excluded. We have checked that the few points far from the regression line in Fig. 12b and d correspond to a large COD at overpass (for OMI) or at noon (for GOME-2). Satellitederived UVI is larger than GB UVI in nearly $70 \%$ of cases for both instruments. The positive relative bias is nearly $4 \%$ for both OMI and GOME-2. A total of $10 \%$ of the cases $\left(p_{90}\right)$ correspond to an SB overestimation of more than about $14 \%$ for OMI and $11 \%$ GOME-2 (Fig. 12 caption). The $p_{10}$ percentiles indicate that only $10 \%$ of the cases correspond to an OMI and GOME-2 underestimation larger than about $8 \%$.

All the statistics of the results are reported in Tables 1 and 2. The median bias is positive: about 0.8 for AS conditions and 0.4 for CS conditions for OMI, about 0.9 for AS conditions and 0.3 for CS conditions for GOME-2. These values 

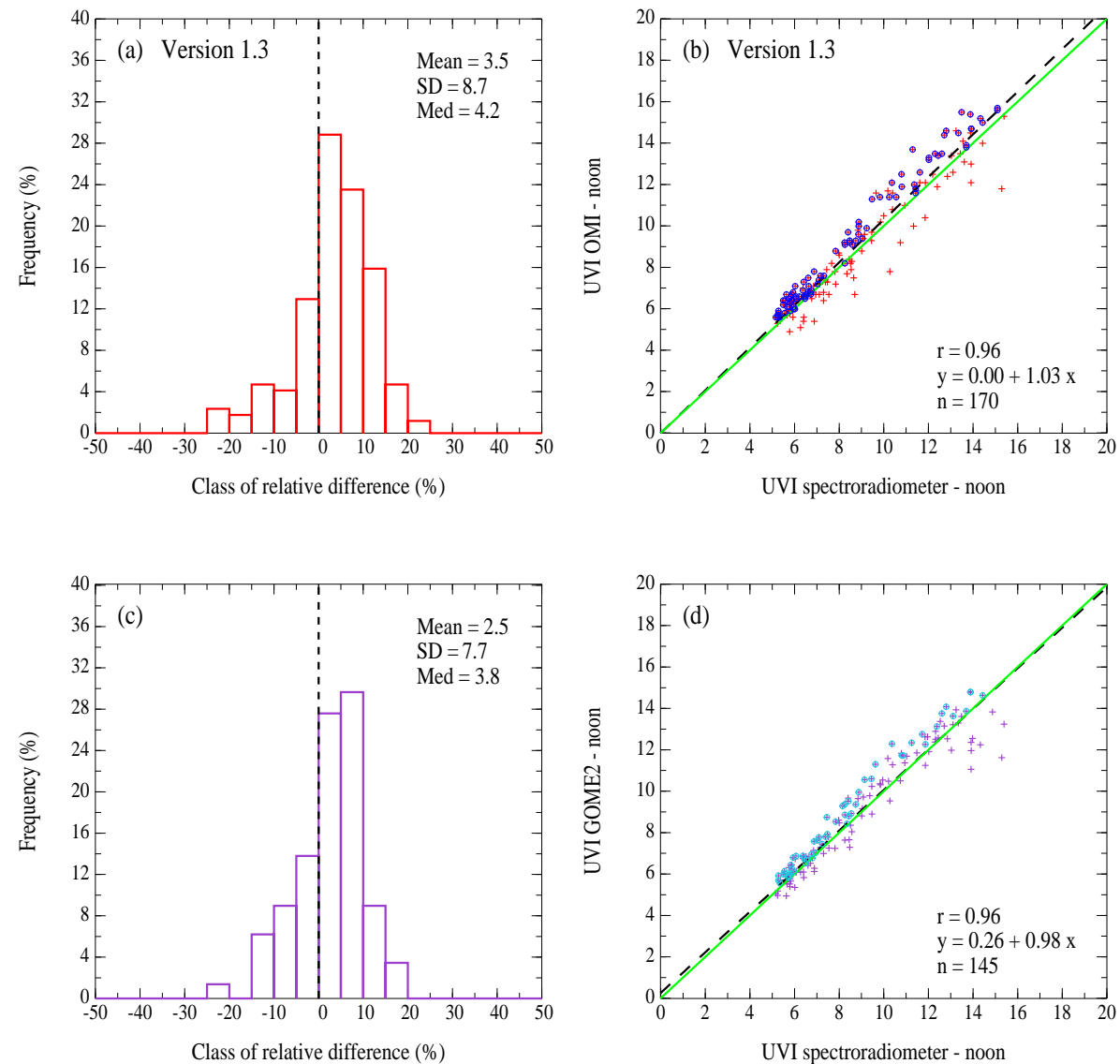

Figure 12. Same as Fig. 2 but for SDR. Percentiles for OMI: $p_{10}=-7.9 \%, p_{90}=13.7 \%$; for GOME-2: $p_{10}=-8.1 \%, p_{90}=10.6 \%$.

are larger than at the two other sites for AS conditions because of the higher UVI levels.

A seasonal variability of the relative difference between GB and SB UVI is observed for both AS and CS conditions for GOME-2, but it seems to be related to the seasonality of the cloudiness rather than to the surface albedo seasonality (not shown).

As at the two other sites, though both satellite instruments overpass at times very far from noon, no correlation between the relative difference and the time difference is observed for AS and CS conditions (not shown).

Radiative transfer calculation results for cloud-free conditions, using tropical ozone, temperature and pressure profiles, are reported in Fig. 5. Figure 5g shows that GB UVI is $3.3 \%$ smaller than simulated UVI, and Fig. 5h shows that OMI UVI is $3.6 \%$ larger, with each bias being smaller than GB and OMI uncertainty, respectively. As at the other sites, this overestimation of OMI UVI is due to differences between the input parameters other than TOC (aerosol parameters (though the aerosol load is small), surface albedo (though this parameter value is small), etc.) and between the two RT models used. Even though the underestimation of GB UVI is within the GB measurement uncertainty, it can be explained since at this site the TOC derived from the GB spectra is also often larger than OMTO3. Figure 5i shows the UVI relative difference between the computed and the GB UVI vs. the TOC relative difference. GB UVI is often smaller than the computed UVI for a negative TOC relative difference, justifying the $3.3 \%$ bias.

Part of the observed positive biases between SB and GB UVI for cloud-free and cloudy conditions can be explained by OMTO3 and GOME-2 TOC underestimation (according to Antón and Loyola, 2011). At this site, aerosol climatology (Kinne et al., 2013) could not contribute much to the biases, since the aerosol load is small. Surface albedo climatology (Tanskanen, 2004) might contribute. According to Kazadzis et al. (2009b), due to the particular situation of SDR (coastal site on a small mountainous island) the cloud cover spatial variability in the satellite pixel should be the main contributor to the SB-GB UVI bias.

The study performed for distances (GB station - CTP/grid cell centre point) smaller than or equal to $10 \mathrm{~km}$ gives results similar to that at the two other sites (Tables 3 and 4). For AS conditions, OMI statistics parameters show a slightly better agreement with GB data compared to the $100 \mathrm{~km}$ distance case. The median relative bias is about $2 \%$ lower, 

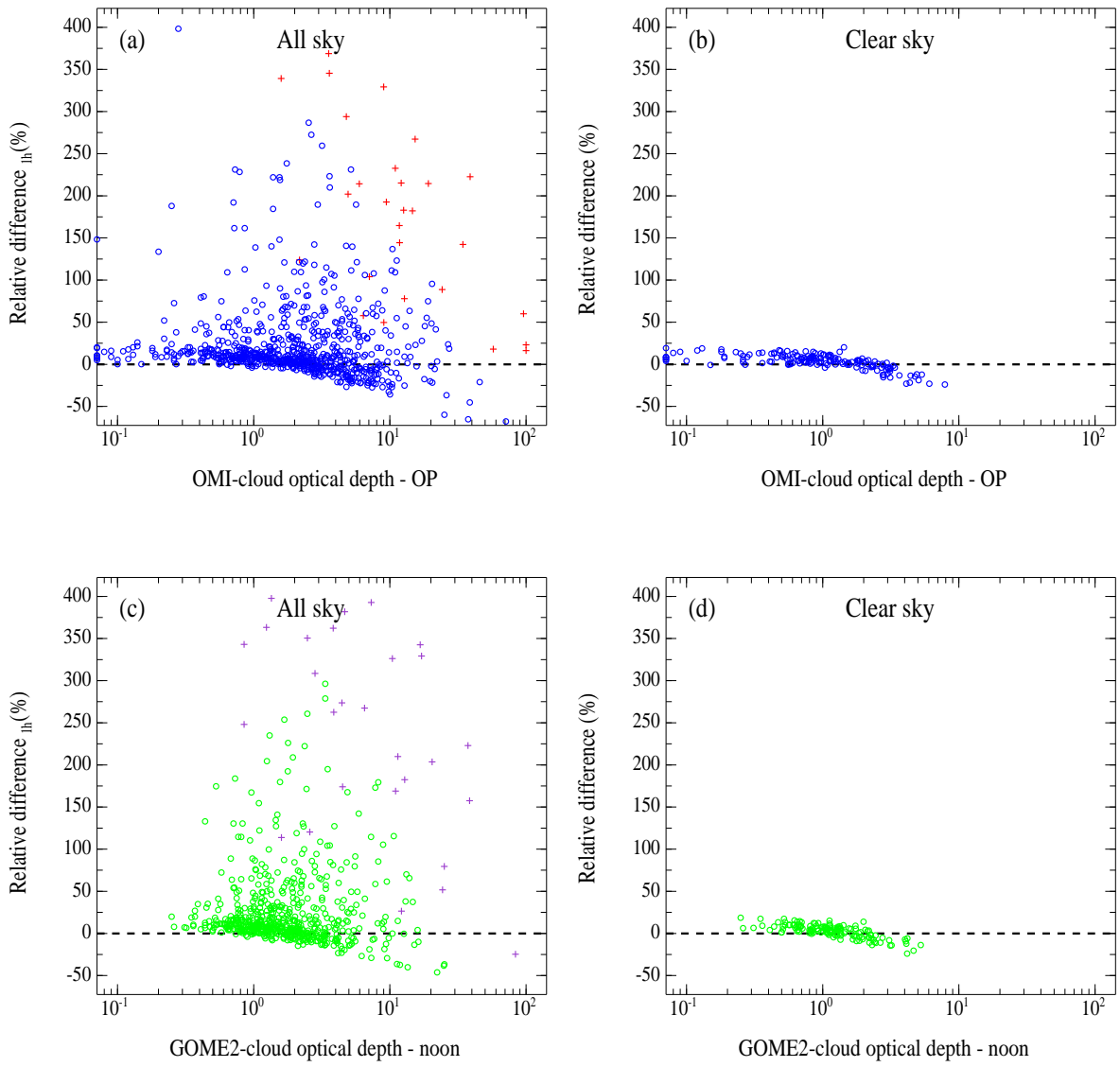

Figure 13. Same as Fig. 3 but for SDR.

$p_{90}$ is much smaller (by about $20 \%$ ), though $p_{10}$, correlation between SB and GB UVI and regression line are nearly the same. For GOME-2, statistics parameters show a worse agreement between SB and GB UVI compared to those for $100 \mathrm{~km}$ distance. The median relative bias is unchanged but $p_{90}$ is larger (by about $15 \%$ ), $p_{10}$ is lower (by about $2 \%$ ), correlation is weaker $(r \sim 0.60)$ and the slope of the regression line is much smaller $(0.62 \pm 0.09)$. Finally, for AS conditions, the filter on the distance has removed cases of large SB UVI overestimations for OMI, and for GOME-2, the overestimation has become larger.

For CS conditions, OMI data compare slightly better with GB data than for the $100 \mathrm{~km}$ case. The median relative bias is nearly unchanged, the overestimation is lower ( $p_{90}$ lower by about $3 \%$ ) and underestimation is stronger ( $p_{10}$ lower by about $5 \%$ ). GOME-2 statistics parameters are little changed compared to $100 \mathrm{~km}$ distance, the GB and SB UVI data show the same strong correlation and the regression line slope $(0.90 \pm 0.07)$ is much smaller than for $100 \mathrm{~km}$ distance but the large uncertainty limits the significance of the difference. This latter case is statistically weakly robust because only 16 UVI pairs are available.

Thus, the comparison of surface UVI from OMI is little improved when smaller distance between the satellite CTP and the GB instrument is considered. For GOME-2, the comparison is worse for AS conditions.

Réunion Island is very mountainous so the effect of surface altitude may be evident in OMI comparison. Tables 3 and 4 show the results accounting for CTP whose altitude is within the sea level and $+250 \mathrm{~m}$ above the site altitude. Whether for AS or CS conditions the statistics parameters are slightly worse, but not significantly, and correlation between SB and GB UVI data is similar. As for OHP site, an altitude selection does not lead to significant changes that is also likely due to the cloudiness estimate and to OMI spatial resolution.

Finally, for AS conditions, about $62 \%$ of both OMI and GOME-2 UVI data agree with GB data in the [-20, 20\%] relative difference interval $(40 \%$ agree in $[-10,10 \%])$. For CS conditions, about $97 \%$ of both OMI and GOME- 2 data agree with GB data in the interval $[-20,20 \%](70$ and $80 \%$ for OMI and GOME-2, respectively, in [-10, 10\%]).

The statistical comparisons restricted to the same dates for both OMI and GOME-2 are reported in Tables 5 and 6. For AS conditions, the correlation between GB and SB UVI data is not very strong but it is better for OMI ( $r \sim$ 0.74 and $r \sim 0.70$ for OMI and GOME-2, respectively). The slopes of the regression lines are much smaller than 1, OMI 
slope being significantly closer to $1(0.91 \pm 0.03$ for OMI, $0.78 \pm 0.03$ for GOME-2) and intercepts are both large and positive (larger for GOME-2). Median relative bias and absolute bias between GB and SB data are slightly smaller for OMI than for GOME-2. For CS conditions, the correlations are strong and the same for both instruments $(r \sim 0.96)$, both regression line slopes are close to 1 (OMI slope $>1$, GOME2 slope $<1$ with a positive intercept), but accounting for the uncertainties the difference is not significant. Median relative biases and absolute bias are slightly larger for OMI than for GOME-2. OMI overestimation is smaller than the GOME2 overestimation for AS conditions $\left(p_{90}\right)$; OMI underestimation is stronger than the GOME-2 overestimation $\left(p_{10}\right)$. For CS conditions, OMI and GOME- $2 p_{90}$ and $p_{10}$ are very close.

As mentioned previously, GOME-2 relative differences between GB and SB UVI data show a seasonal variability related to cloud presence, while there is no variability for OMI.

The validation of previous OMI v1.2 UVI data with GB data does not show significant differences, as observed in Tables 1 and 2. Indeed, for AS conditions, the correlation between GB and SB UVI data is slightly weaker and the regression line slope is slightly worse than for v1.3 data, but the other statistics parameters are very similar for both versions. For CS conditions, the correlation between GB and SB UVI data is slightly weaker and the regression line slope is nearly the same as for v1.3 data, but the other statistics parameters are worse. Overall, these changes are weak and not significant. The small difference between the v1.2 and v1.3 data sets is due to the small AOD (Fig. 6a, blue dashed line) and large SSA (Fig. 6b). Thus, the correction factor at SDR is close to unity (Fig. 6c).

\section{Conclusion}

Validation of satellite noon UVI products from OMI (v1.3) and GOME-2 (v1.13) with ground-based measurements of UVI at noon has been carried out at three sites. The three sites are very different regarding the topography and the environment. One is an urban site in a topographically flat region in the north of France (VDA). The second site is a rural mountainous site in the southern French Alps (OHP). The third one is a coastal urban site on a small mountainous island in the southern tropics (SDR). Moreover, the overpass of the two satellites occurs often far from solar noon at all sites, rendering the estimate of noon UVI a challenge due to the difficulty to estimate the actual cloudiness at noontime. The sites are each equipped with spectroradiometers affiliated with the Network for the Detection of Atmospheric Composition Change.

SDR is difficult for spatial UV estimates because of (i) the mountainous topography of Réunion Island, and thus the frequent formation of clouds at around midday and (ii) the satel- lite pixel covering both land and ocean, for which the cloud cover are likely different. The space-based total ozone retrieval and the cloud correction factor are affected, which in turn affects the satellite-based UVI estimate, as observed by Antón and Loyola (2011) and by Kazadzis et al. (2009b). The two other sites encounter less diurnal cloud cover variation and thus are expected to be more favourable for UV estimates. Nevertheless, these two latter sites are affected by aerosols caused by air pollution whose absorption should be accounted for in the satellite algorithms. Thus, aerosol and cloud cover inhomogeneities in the satellite pixel make the validation difficult at each ground-based site.

OMI v1.3 UVI products, derived from v1.2 products using a correction factor to account for absorbing aerosols, show much better agreement with GB UVI measurements at VDA and OHP. The relative bias between SB and GB data is reduced by $8-12 \%$, in agreement with Arola et al. (2009).

On average, for both space-borne sensors, the median relative biases are in the 8.4-12.5\% and 3.8-8.4\% ranges for all sky and clear sky conditions, respectively. Thus, accounting for the uncertainties in their UVI data (see Sect. 2), satellitebased and ground-based measurements agree for AS conditions and the agreement is good for CS conditions. We could even suggest that OMI and GOME-2 uncertainties (see Sect. 2.2.1 and 2.2.2, respectively) are overestimated.

For both all sky and cloud-free conditions, the correlations are strong at VDA and OHP, meaning that the variability in actual UVI is retrieved in satellite-based estimates. At SDR, the correlations are strong for cloud-free conditions and weaker for cloudy cases.

The 90th percentiles indicate that for all sky conditions, $10 \%$ of the cases correspond to relative differences larger than about $70 \%$ at VDA and OHP for both space-borne instruments. These $10 \%$ of cases correspond to UVI lower than 3 , meaning that the comparisons are much better for high UVI than for low UVI. At SDR, for all sky conditions, $10 \%$ of the relative differences are larger than about $85 \%$ for OMI and $100 \%$ for GOME-2. At SDR, UVI is often large so this strong overestimation is related to the site environment.

Underestimation of UVI by the space-borne instruments is more risky than overestimation for public health. The 10th percentiles indicate that $10 \%$ of the cases have a relative difference lower than $-17 \%$ at VDA, $-12 \%$ at OHP and $-10 \%$ at SDR. For example, a $17 \%$ underestimation for $\mathrm{UVI}=6$ means that the actual UVI value is 7 , and a $10 \%$ underestimation for a high UVI, i.e. UVI $=15$, implies an actual value 16.5 , which has more important consequences than overestimations. However, these cases are not very frequent.

For the three sites, the distance between the ground-based site and the OMI cross-track position/GOME-2 grid cell centre point, as well as the environment topography are not critical, likely because of the rather coarse spatial resolution of the satellite instruments. 
Considering the statistics parameters when the comparison of SB and GB UVI data is restricted to common dates, we observe that, for AS conditions, absolute bias and regression line slope are slightly worse for GOME-2 than for OMI at all sites, while relative bias and correlation coefficient are similar for both satellite instruments. For CS conditions, the three sites give different results. Indeed, in terms of absolute bias, OMI UVI agree with GB data slightly better than GOME2 UVI at VDA, OMI and GOME-2 UVI products compare with GB data equally at OHP, while at the SDR site GOME2 UVI agree with GB data slightly better than OMI UVI. In terms of median relative bias, OMI and GOME-2 data agree with GB data equally at VDA, while it is slightly better at OHP and SDR for GOME-2. This later behaviour means that the absence of clouds at noon (CS conditions) is slightly better forecast by GOME-2 via COD estimates in the morning and in the afternoon. However, the differences are subtle and globally the algorithms work equally well.

Such positive biases as obtained in this work, which for OMI v1.3 are in agreement with other studies (Muyimbwa et al., 2015; Bernhard et al., 2015), might be partly explained by the satellite total ozone column underestimation, as shown in the modelling study of the present work. However, further studies are still needed to understand and reduce the remaining existing biases between satellite-based and ground-based surface UVI at the three sites. OMI v1.3 offline correction uses a climatology for aerosol optical properties, so a reduction of the OMI bias might be obtained via a better characterization of these aerosol properties, for example, from simultaneous measurements. This recommendation is worth considering also for GOME-2. For GOME-2, the role of subpixel inhomogeneity could be investigated with respect to aerosol and cloud spatial variability, similar to what has been done for OMI (Weihs et al., 2008; Kazadzis et al., 2009b).
Finally, the UVI estimates derived from satellite sensors OMI and GOME-2 are only weakly biased high (on average less than 0.5 units of UVI at VDA and OHP and less than 1 at SDR), which, as mentioned above, is less risky for public health than a low bias, and thus OMI and GOME-2 noon UVI data sets are quite reliable and can be used by the public.

\section{Data availability}

Spectroradiometer measurements are currently available at http://www-loa.univ-lille1.fr/index.php/observation/sites. html and at ftp://ftp.cpc.ncep.noaa.gov/ndacc/station/.

OMI data are available at http://avdc.gsfc.nasa.gov/index. php?site $=595385375 \&$ id $=79$. GOME- 2 data are available at http://o3msaf.fmi.fi/offline_access.html. The reprocessed GOME-2 data prepared for this study are available on request. 


\section{Appendix A: Statistics definitions for $n$ pairs}

of UVI data

Table A1. Table of statistics definitions.

\begin{tabular}{|c|c|}
\hline Difference & $\operatorname{diff}_{i}=\mathrm{SB}_{i}-\mathrm{GB}_{i}$ \\
\hline Mean bias (mean difference) & $\operatorname{mBias}=\frac{1}{n} \sum_{i=1}^{n} \operatorname{diff}_{i}$ \\
\hline Root mean square difference & $\mathrm{RMS}=\sqrt{\frac{1}{n-1}} \sum_{i=1}^{n}\left(\operatorname{diff}_{i}\right)^{2}$ \\
\hline Relative difference in \% & $\operatorname{rdiff}_{i}=100 \times \frac{\mathrm{SB}_{i}-\mathrm{GB}_{i}}{\mathrm{~GB}_{i}}$ \\
\hline Mean relative bias (mean relative difference) in $\%$ & $\operatorname{mrBias}=\frac{1}{n} \sum_{i=1}^{n} \operatorname{rdiff}_{i}$ \\
\hline Root mean square relative difference & $\mathrm{rRMS}=\sqrt{\frac{1}{n-1} \sum_{i=1}^{n}\left(\operatorname{rdiff}_{i}\right)^{2}}$ \\
\hline Standard deviation of the relative differences (dispersion around the mean) & $\mathrm{SD}=\sqrt{\frac{1}{n-1} \sum_{i=1}^{n}\left(\operatorname{rdiff}_{i}-\mathrm{mrBias}^{2}\right.}$ \\
\hline Median bias (UVI) & Middle value of the differences \\
\hline Median relative bias $(\%)$ & Middle value of the relative differences \\
\hline Relative difference values at the 10th and 90th percentiles & $p_{10}, p_{90}$ \\
\hline
\end{tabular}

Since differences and relative differences distributions are skewed, median parameters and percentiles are also used. 
Author contributions. Colette Brogniez and Frédérique Auriol oversaw the measurements. Colette Brogniez prepared the manuscript with contributions from Antti Arola, Jukka Kujanpää, Frédérique Auriol, Mikko Riku Aleksi Pitkänen and Niilo Kalakoski. The instruments were operated by Frédérique Auriol, Maxime Catalfamo, Jean-Marc Metzger, Guy Tournois and Pierre Da Conceicao. Christine Deroo contributed to collecting data and processing them. Colette Brogniez, Antti Arola, Jukka Kujanpää, Mikko Riku Aleksi Pitkänen, Niilo Kalakoski and Béatrice Sauvage contributed to the analysis of the results.

Acknowledgements. Colette Brogniez thanks several LOA members: L. Labonnote for helpful discussions, R. De Filippi for automation of data transfer and F. Ducos for writing a helpful script. P. Goloub and T. Podvin are acknowledged for their help in selecting the AERONET/PHOTONS data. The sites are supported by CNES within the French program TOSCA. The SDR site is also supported by "la région La Réunion". Development of the OUV product has been partly funded by EUMETSAT.

Edited by: H. Maring

Reviewed by: three anonymous referees

\section{References}

Antón, M. and Loyola, D.: Influence of cloud properties on satellite total ozone observations, J. Geophys. Res., 116, D03208, doi:10.1029/2010JD014780, 2011.

Antón, M., Piedehierro, A. A., Alados-Arboledas, L., Wolfran, E., and Olmo, F. J.: Extreme ultraviolet index due to broken clouds at a midlatitude site, Granada (southeastern Spain), Atmos. Environ., 118, 10-14, 2012.

Arola, A., Kazadzis, S., Lindfors, A., Krotkov, N., Kujanpää, J., Tamminen, J., Bais, A., di Sarra, A., Villaplana, J. M., Brogniez, C., Siani, A. M., Janouch, M., Weihs, P., Webb, A., Koskela, T., Kouremeti, N., Meloni, D., Buchard, V., Auriol, F., Ialongo, I., Staneck, M., Simic, S., Smedle, A., and Kinne, S.: A new approach to correct for absorbing aerosols in OMI UV, J. Geophys. Res., 36, L22805, doi:10.1029/2009GL041137, 2009.

Bernhard, G. and Seckmeyer, G.: Uncertainty of measurements of spectral solar UV irradiance, J. Geophys. Res., 104, 1432114345, 1999.

Bernhard, G., Arola, A., Dahlback, A., Fioletov, V., Heikkilä, A., Johnsen, B., Koskela, T., Lakkala, K., Svendby, T., and Tamminen, J.: Comparison of OMI UV observations with ground-based measurements at high northern latitudes, Atmos. Chem. Phys., 15, 7391-7412, doi:10.5194/acp-15-7391-2015, 2015.

Buchard, V., Brogniez, C., Auriol, F., Bonnel, B., Lenoble, J., Tanskanen, A., Bojkov, B., and Veefkind, P.: Comparison of OMI ozone and UV irradiance data with ground-based measurements at two French sites, Atmos. Chem. Phys., 8, 4517-4528, doi:10.5194/acp-8-4517-2008, 2008.

Buntoung, S. and Webb, A. R.: Comparison of erythemal UV irradiances from Ozone Monitoring Instrument (OMI) and groundbased data at four Thai stations, J. Geophys. Res., 115, D18215, doi:10.1029/2009JD013567, 2010.
Diffey, B. and McKinlay, A. F.: A reference action spectrum for ultraviolet induced erythema in human skin, Human Exposure to UV radiation: Risks and Regulations, 83-87, Elsevier, NY, 1987.

Dobber, M., Voors, R., Dirksen, R., Kleipool, Q., and Levelt, P.: The High-Resolution Solar Reference Spectrum between 250 and $550 \mathrm{~nm}$ and its Application to Measurements with the Ozone Monitoring Instrument, Solar Phys., 249, 281-291, doi:10.1007/s11207-008-9187-7, 2008.

Feister, U. and Grewe, R.: Spectral albedo measurements in the UV and visible region over different types of surfaces, Photochem. Photobiol., 62, 736-744, 1995.

GOME-2 Product guide: Doc. EUMETSAT No EUM/OPSEPS/MAN/07/0445, Issue: v3, 17 March 2011.

Gröbner, J., Schreder, J., Kazadzis, S., Bais, A. F., Blumthaler, M., Görts, P., Tax, R., Koskela, T., Seckmeyer, G., Webb, A. R., and Rembges, D.: Traveling reference spectroradiometer for routine quality assurance of spectral solar ultraviolet irradiance measurements, Appl. Optics, 44, 5321-5331, doi:10.1364/AO.44.005321, 2005.

Holben, B. N., Eck, T. F., Slutsker, I., Tanré, D., Buis, J. P., Setzer, A., Vermote, E., Reagan, J. A., Kaufman, Y. J., Nakajima, T., Lavenu, F., Jankowiak, I., and Smirnov, A.: AERONET - A federated instrument network and data archive for aerosol characterization, Remote Sens. Environ., 66, 1-6, 1998.

Houët, M.: Spectroradiométrie du rayonnement Solaire UV au sol: Améliorations apportées à l'instrumentation et au traitement des mesures, Analyse pour l'évaluation du contenu atmosphérique en ozone et en aérosols, PhD thesis, Univ. of Lille, France, 2003.

Houët, M. and Brogniez, C.: Ozone column retrieval from solar UV irradiance measurements at ground level: Sensitivity tests and uncertainty estimation, J. Geophys. Res., 109, D15302, doi:10.1029/2004JD004703, 2004.

Ialongo, I., Casale, G. R., and Siani, A. M.: Comparison of total ozone and erythemal UV data from OMI with ground-based measurements at Rome station, Atmos. Chem. Phys., 8, 3283-3289, doi:10.5194/acp-8-3283-2008, 2008.

Kalakoski, N.: O3M SAF Validation Report, Offline UV Index, SAF/O3M/FMI/VR/OUV/091, FMI, available at: http://o3msaf. fmi.fi/docs/vr/Validation_Report_OUV_Feb_2009.pdf (last access: 21 November 2016), 2009.

Kazadzis, S., Bais, A., Arola, A., Krotkov, N., Kouremeti, N., and Meleti, C.: Ozone Monitoring Instrument spectral UV irradiance products: comparison with ground based measurements at an urban environment, Atmos. Chem. Phys., 9, 585-594, doi:10.5194/acp-9-585-2009, 2009a.

Kazadzis, S., Bais, A., Balis, D., Kouremeti, N., Zempila, M., Arola, A., Giannakaki, E., Amiridis, V., and Kazantzidis, A.: Spatial and temporal UV irradiance and aerosol variability within the area of an OMI satellite pixel, Atmos. Chem. Phys., 9, 4593-4601, doi:10.5194/acp-9-4593-2009, 2009 b.

Kinne, S.: Towards an observation-tied AOD climatology, presentation in AT2 Aerosol Workshop, Bremen, June 2007.

Kinne, S., O’Donnel, D., Stier, P., Kloster, S., Zhang, K., Schmidt, H., Rast, S., Giorgetta, M., Eck, T. F., and Stevens, B.: MACv1: A new global aerosol climatology for climate studies, J. Adv. Model. Earth Syst., 5, 704-740, doi:10.1002/jame.20035, 2013.

Köpke, P., Hess, M., Schult, I., and Shettle, E. P.: Global Aerosol Data Set, Report No. 243, Max-Planck-Institut für Meteorologie, Hamburg, ISSN 0937-1060, 1997. 
Krotkov, N. A., Herman, J., Bhartia, P. K., Seftor, C., Arola, A., Kaurola, J., Taalas, P., and Vasilkov, A.: OMI Surface UV Irradiance Algorithm, in OMI Algorithm Theoretical Basis Document, Volume III: Clouds, Aerosols, and Surface UV Irradiance, ATBD-OMI-03, available at: http://eospso.gsfc.nasa.gov/eos_ homepage/for_scientists/atbd/docs/OMI/ATBD-OMI-03.pdf (last access: 21 November 2016), 2002.

Kujanpää, J.: Algorithm Theoretical Basis Document, Offline UV (OUV) Products, SAF/O3M/FMI/ATBD/001,FMI, available at: http://o3msaf.fmi.fi/docs/atbd/Algorithm_Theoretical_ Basis_Document_OUV_Jun_2013.pdf (last access: 21 November 2016), 2013.

Kujanpää, J. and Kalakoski, N.: Operational surface UV radiation product from GOME-2 and AVHRR/3 data, Atmos. Meas. Tech., 8, 4399-4414, doi:10.5194/amt-8-4399-2015, 2015.

Levelt, P. F., van den Ooord, G. H. J., Dobber, M. R., Mälkki, A., Visser, H., de Vries, J., Stammes, P., Lundell, J. O. V., and Saari, H.: The Ozone Monitoring Instrument, IEEE T. Geosci. Remote Sens., 44, 1093-1101, 2006.

McKenzie, R. L., Johnston, P. V., Smale, D., Bodhaine, B. A., and Madronich, S.: Altitude effects on UV spectral irradiance deduced from measurements at Lauder, New Zealand, and at Mauna Loa Observatory, Hawaii, J. Geophys. Res., 106, 22845-22860, 2001.

Munro, R., Lang, R., Klaes, D., Poli, G., Retscher, C., Lindstrot, R., Huckle, R., Lacan, A., Grzegorski, M., Holdak, A., Kokhanovsky, A., Livschitz, J., and Eisinger, M.: The GOME2 instrument on the Metop series of satellites: instrument design, calibration, and level 1 data processing - an overview, Atmos. Meas. Tech., 9, 1279-1301, doi:10.5194/amt-9-1279-2016, 2016.

Muyimbwa, D., Dahlback, A., Ssenyonga, T., Chen, Y.-C., Stamnes, J. J., Frette, Ø., and Hamre, B.: Validation of ozone monitoring instrument ultraviolet index against ground-basedUV index in Kampala, Uganda, Appl. Optics, 54, 8537-8545, doi:10.1364/AO.54.008537, 2015.
Paur, R. J. and Bass A.: The ultraviolet cross sections of ozone: II. Results and temperature dependence, in: Atmospheric Ozone, Proceedings of the Quadrennial Ozone Symposium, Halkidiki, Greece, edited by: Zeferos, C. and Ghazi, A., 611-616, D. Reidel, Norwell, Mass., 1985.

Stamnes, K., Tsay, S.-C., Wiscombe, W., and Jayaweera, K.: Numerically stable algorithm for discrete-ordinatemethod radiative transfer in multiple scattering and emitting layered media, Appl. Optics, 27, 2502-2509, 1988.

Tanskanen, A.: Lambertian surface albedo climatology at $360 \mathrm{~nm}$ from TOMS data using moving time-window technique, Proc. XX Quadrennial Ozone Symposium, June 2004.

Tanskanen, A., Lindfors, A., Määttä, A., Krotkov, N., Herman, J., Kaurola, J., Koskela, T., Lakkala, K., Fioletov, V., Bernhard, G., McKenzie, R., Kondo, Y., O’Neill, M., Slaper, H., den Outer, P., Bais, A. F., and Tamminen, J.: Validation of daily erythemal doses from Ozone Monitoring Instrument with groundbased UV measurement data, J. Geophys. Res., 112, D24S44, doi:10.1029/2007JD008830, 2007.

Van Weele, M., Martin, J., Blumthaler, M., Brogniez, C., Den Outer, P. N., Engelsen, O., Lenoble, J., Mayer, B., Pfister, G., Ruggaber, A., Walravens, B., Weihs, P., Gardiner, B. G., Gillotay, D., Haferl, D., Kylling, A., Seckmeyer, G., and Wauben, W. M. F.: From model intercomparison toward benchmark UV spectra for six real atmospheric cases, J. Geophys. Res., 105, 4915-4925, 2000.

Weihs, P., Blumthaler, M., Rieder, H. E., Kreuter, A., Simic, S., Laube, W., Schmalwieser, A. W., Wagner, J. E., and Tanskanen, A.: Measurements of UV irradiance within the area of one satellite pixel, Atmos. Chem. Phys., 8, 5615-5626, doi:10.5194/acp8-5615-2008, 2008.

York, D., Evensen, N. M., López Martínez, M., and De Basabe Delgado, J.: Unified equations for the slope, intercept, and standard errors of the best straight line, Am. J. Phys., 72, 367, doi:10.1119/1.1632486, 2004. 